\title{
Market mechanisms and funding dynamics in equity crowdfunding 2 个
}

\author{
Lars Hornuf ${ }^{\mathrm{a}, \mathrm{b}, \mathrm{c}}$, Armin Schwienbacher ${ }^{\mathrm{d}, *}$ \\ ${ }^{a}$ University of Bremen, Business Studies \& Economics, Hochschulring 4, 28359 Bremen, Germany \\ ${ }^{\mathrm{b}}$ Max Planck Institute for Innovation and Competition, Marstallplatz 1, 80539 Munich, Germany \\ ' CESifo, Poschingerstraße 5, 81679 Munich, Germany \\ d SKEMA Business School-Université Côte d'Azur, SKEMA Business School, Lille Campus, Department of Finance and Accounting, Avenue Willy Brandt, F - 59777 Euralille, \\ France
}

\section{A R T I C L E I N F O}

Article history:

Received 31 October 2016

Received in revised form 3 August 2017

Accepted 29 August 2017

Available online $\mathrm{xxxx}$

\section{JEL classifications:}

G11

G20

K22

M13

Keywords:

Equity crowdfunding

Crowdinvesting

Startups

Securities issuance

Investment dynamics

Entrepreneurial finance

\begin{abstract}
A B S T R A C T
Equity crowdfunding is a new form of entrepreneurial finance, in which investors do not receive perks or engage in pre-purchase of the product, but rather participate in the future cash flows of a firm. In this paper, we analyze what determines individual investment decisions in this new financial market. One important factor that may influence the behavior of investors is the way the portal allocates securities. We use unique data from four German equity crowdfunding portals to examine how the allocation mechanism affects funding dynamics. In contrast with the crowdfunding campaigns on Kickstarter, on which the typical pattern of project support is U shaped, we find that equity crowdfunding dynamics are L shaped under a first-come, first-served mechanism and $U$ shaped under a second-price auction. The evidence also shows that investors base their decisions on information provided by the entrepreneur in the form of updates as well as by the investment behavior and comments of other crowd investors.
\end{abstract}

(C) 2017 The Authors. Published by Elsevier B.V. This is an open access article under the CC BY license (http://creativecommons.org/licenses/by/4.0/).

\section{Introduction}

In recent years, crowdfunding has become a mainstream source of funding for early-stage firms. Equity crowdfunding (also referred to as investment-based crowdfunding, securities-based crowdfunding, and crowdinvesting) is a sub-category of

it We thank Massimo Colombo, Douglas Cumming, Alexander Groh, Tobin Hanspal, Dietmar Harhoff, Mingfeng Lin, Jay Ritter, Denis Schweizer, Elisabeth Schulte, Oscar Stolper, and the participants in the MACIE Research Seminar (Marburg University), the 7th Economic Workshop (University of Trier), the Law and Economics Forum (London School of Economics), the Workshop of Entrepreneurship and Innovation (University of Trier), the Annual Meeting of the Verein für Socialpolitik (University of Münster), the 3rd International Conference on the Dynamics of Entrepreneurship (Mannheim University/Centre for European Economic Research), the ENTFIN Conference Lyon 2016 (EM Lyon), seminars at the University of Bonn, Schulich School of Business (York University), John Molson School of Business (Concordia University), SKEMA Business School, the Max Planck Institute for Innovation and Competition, GREQAM at Aix-Marseille School of Economics, Montpellier Business School, and the Jean Monnet Inter-University Centre of Excellence (University of Rijeka) for their thoughtful comments and suggestions. We thank Gerrit Engelmann and Florian Pregler for their excellent research assistance. This article evolved as part of the research project "Crowdinvesting in Germany, England and the USA: Regulatory Perspectives and Welfare Implications of a New Financing Scheme," which was supported by the German Research Foundation (Deutsche Forschungsgemeinschaft) under the grant number HO 5296/1-1.

* Corresponding author.

E-mail addresses: hornuf@uni-bremen.de (L. Hornuf), armin.schwienbacher@skema.edu (A. Schwienbacher). 
crowdfunding in which firms issue financial securities to satisfy their capital needs. At this point, empirical research on equity crowdfunding is still scarce, because this market segment was not available until only recently to the general crowd in jurisdictions such as the United States or lacked specific regulation elsewhere to facilitate its development (Hornuf and Schwienbacher, 2017b).

Some seminal articles on equity crowdfunding have described the size, growth, and geographic distributions of the market (Vulkan et al., 2016; Günther et al., 2017), have analyzed the static factors that affect funding success based on ultimate campaign outcome (Ahlers et al., 2015; Hornuf and Schwienbacher, 2017a), and have provided first insights into the returns on investment (Hornuf and Schmitt, 2016; Signori and Vismara, 2016). Agrawal et al. (2016) show that syndicates help well-informed lead investors in equity crowdfunding extend their knowledge to a less well-informed crowd that is consequently willing to invest in a company. In a similar vein, Vismara (2017) evidences that founders have a greater chance of reaching the funding goal in an equity crowdfunding campaign if they possess more social capital as measured by the number of the founder's LinkedIn connections.

More recently, scholars have focused on the dynamic effects of equity crowdfunding. As the first researcher to assess dynamics in equity offerings, Vismara (2017) shows that information cascades among individual investors are an important factor in the equity crowdfunding investment process. By running a cross-sectional analysis on the portal Crowdcube, he finds that investments in the early days of a campaign are important in attracting investors later on and consequently increase the probability of funding success. These findings highlight the existence of dynamic effects within campaigns that are generally overlooked in other studies. Another recent article investigates whether information disclosure in the form of updates affects the investment dynamics on Companisto and Seedmatch (Block et al., 2017). The authors find that startups can provide credible information about their quality when posting updates about their new developments, such as funding events, business developments, and cooperation projects.

None of these studies, however, have examined how different share allocation mechanisms affect investments by the crowd. A distinct aspect of equity crowdfunding is that financial securities can be allocated to investors in different ways. Knowing which market mechanisms make a funding successful is important for entrepreneurs and portal managers. In contrast with rewardbased crowdfunding, two models are commonly used in equity crowdfunding: the first-come, first-served (FCFS) and the auction mechanism. The choice of market mechanism is likely to influence the dynamics of investor behavior during the campaign. For example, because prices remain constant under the FCFS mechanism, investors have no incentive to withhold their bids and may bid early to maximize their chances of obtaining securities. Under an auction mechanism, investors may prefer to wait until the end so as not to disclose their interests in buying securities, which could induce more demand. In this case, a stronger end effect may occur, shifting the dynamics of individual investments toward the end of the campaign.

The current research adds to the literature on funding dynamics in equity crowdfunding by investigating how the functioning of different market mechanisms that determine the allocation of securities to investors affects the investment process. In addition to the allocation mechanisms, we examine the effects of permitting investors to comment on their investments and making the amounts pledged visible to peer investors. We test our predictions using a comprehensive dataset of individual investments made on four different portals in Germany. In contrast with the crowdfunding campaigns on Kickstarter, on which the typical pattern of project support is $U$ shaped, we find that the mechanism used to allocate securities affects equity crowdfunding dynamics. When the allocation occurs on an FCFS basis, equity crowdfunding dynamics are L shaped, and we observe a relatively weak end-of-campaign effect. This suggests that there is a collective attention effect during the first days of the campaign but no late bidding triggered by run-ups or sniping. This L-shaped pattern occurs even though equity crowdfunding campaigns are not open-ended, which contrasts with most reward-based crowdfunding campaigns. Indeed, waiting until the end is risky because crowd investors face the chance of no longer being able to invest after all shares are allocated.

However, on Innovestment, an equity crowdfunding portal running a second-price auction, the dynamics of backer support are U shaped. Next to the collective attention at the start of the campaign, we document a sharp increase in investor support by the end of the funding process. For example, the average number of daily investments made in a campaign increases by approximately $40 \%$ after $90 \%$ of the funding limit is reached. Under a second-price auction mechanism, it might be worthwhile for crowd investors to put their investment decisions off until the campaign ends. This is because bids reveal private information about the value of the firm to other investors, creating more capital supply that drives up the price per ticket. In addition, when securities are allocated through an auction mechanism, the campaign will not be stopped prematurely even if investors have bought off all the available securities. At first glance, the Innovestment second-price auction has the desirable property of allocating resources more efficiently (Vickrey, 1961; Kagel and Levin, 2001), because individual investors make sealed bids on Innovestment. However, although individual bids are sealed, investors can still see the currently applicable second price of the campaign, which largely suspends the classic feature of a Vickrey auction. Furthermore, we find that a smaller proportion of firms receive funding under the auction mechanism. Whether this is because investors do not understand the more complex rules of a second-price auction or because investors only pick the firms with better future prospects can only be analyzed after reliable data on ultimate campaign outcomes become available.

Furthermore, we document that investors consider information provided by entrepreneurs in the form of updates as well as peer investments and comments posted by other investors. The effect is most pronounced when an investor's comment contains potentially valuable feedback on the product or market, that is, when the comment suggests that the crowd investor knows the product or claims to be an expert in the field of the entrepreneurial firm and offers personal help to the founder. Claims of second-time investments by earlier investors also positively affect the investment decisions of other funders. Thus, comments induce other investors to participate, even though they are not able to verify whether the claims made are accurate. 
The structure of this article is as follows: in Section 2, we describe the German equity crowdfunding market, in particular the business model under which different portals operate. In Section 3, we formulate hypotheses on different allocation mechanisms, the influence of information, and behavioral aspects. Section 4 presents the data and methodology. Section 5 outlines the empirical results, and Section 6 concludes.

\section{Equity crowdfunding in Germany}

\subsection{Defining equity crowdfunding}

Equity crowdfunding is a category of crowdfunding, in which backers expect financial compensation for their investment. To motivate the crowd to participate in the future profits of the firm, fundraisers in some jurisdictions offer equity shares in a private limited liability company (LLC), as is the case on portals such as Crowdcube or Seedrs (Vismara, 2016) in the United Kingdom. In Germany, startups do not offer common shares in an LLC, as this would require the involvement of a costly notary (Braun et al., 2013). Nevertheless, common shares of a public LLC have been used in one large campaign by the German portal Bergfürst, which has also established a secondary market on which securities can be freely traded. Typically, German startups running an equity crowdfunding campaign use mezzanine financial instruments such as subordinated profit-participating loans (so-called partiarische Darlehen) or silent partnerships, which represent a virtual share in the startup that is mimicked by contract law. The market in Germany might therefore reflect a "quasi-equity" crowdfunding market. Nevertheless, the way crowdfunding takes place in Germany is not as particular. For example, Indiegogo-the main competitor of Kickstarter-allows startups to run equity crowdfunding campaigns on its portal, ${ }^{1}$ many of which use similar financial contracts to those used on the German market. In Belgium, MyMicroInvest uses participating notes, which also share some characteristics with the instruments used in Germany.

Before the campaign goes online, the startup and the portal must agree on a valuation of the firm, and the founders must decide how much capital they want to raise. Depending on the valuation and capital needs of the firm, the portal provides a standardized financial contract so that the crowd can participate in the future cash flows of the startup. As mentioned previously, the crowd generally holds a mezzanine financial instrument in the quasi-equity crowdfunding markets in Germany, which ranks above ordinary shares and shareholder loans but below all ordinary liabilities. These financial instruments cannot be sold on a secondary market and often have a life span of three to seven years. In the past, many startups raised 100,000 EUR and offered 250 EUR tickets to the investors. If the firm value was, for example, determined to be 1,000,000 EUR, an investor buying a single ticket obtained a right to $0.023 \%$ of the future cash flows of the firm. It is important to note that in this case, the firm neither sells existing shares of the LLC nor issues new shares. Rather, investors in these quasi-equity crowdfunding markets simply hold a right to receive a pro-rata payment of the firm's profits without any of the rights attached to an equity share, such as voting rights. Although investors do not participate in the losses of the firm (margin requirements do not exist), there is a high risk that the startup will fail and investors will not receive any financial return from the securities bought. Moreover, in many cases investors might even lose their original principal investment.

\subsection{Equity crowdfunding portals in Germany}

Equity crowdfunding portals in Germany largely follow the business model outlined in Section 2.1. Nevertheless, some of them have adopted slightly different business practices to differentiate themselves from their competitors. It is worth outlining the similarities and major differences across the four portals under consideration in this study because they might affect the funding dynamics.

First, early movers can establish a large and overall more solvent user base over time. These portals can mobilize a greater supply of capital, and they possess the reputation of running serious campaigns. By the year 2016, 59 equity crowdfunding portals were established on the German market, 37 of which had hosted one or more successful campaigns (Dorfleitner et al., 2017). During our observation period, three of these portals made up $85 \%$ of the market share in terms of capital raised and $82 \%$ when considering the number of startups that got funded. These three portals were Seedmatch, Innovestment, and Companisto.

Seedmatch and Innovestment successfully funded their first campaigns in late 2011 and were the first portals to operate on the German market. Companisto joined a year later but soon caught up with the other two portals. United Equity is a smaller portal, and it accomplished its first successful campaign in 2013. Because of its status as a latecomer, United Equity does not benefit from the user base and reputation of the somewhat older portals. Funding a specific amount of money on United Equity thus takes longer, and the campaign suffers from a higher risk of not being completed successfully. This situation is in line with the empirical evidence provided subsequently, as funding periods are generally shorter for Seedmatch, Innovestment, and Companisto.

Second, most often backers make a direct investment in the startup in which they want to hold securities. During our observation period, this held true for financial contracts of all but one German portal. Companisto set up a special purpose vehicle that pools the investments made in each campaign run on the portal and then invests the capital raised from the crowd in the startup in which these investors want to hold securities. ${ }^{2}$ After the equity crowdfunding has taken place, the pooled investment helps venture capital firms negotiate with a single counterparty and makes buying-out the crowd easier. While more confident founders

\footnotetext{
1 See https://equity.indiegogo.com.

2 Nowadays, Companisto uses a pooling and carry agreement, which serves the same purpose.
} 
might ex ante prefer such a contract design, as it allows them to sell shares to a venture capitalist more easily, it is not apparent why pooled investments should influence the funding dynamics at a particular point in time of the investment cycle.

Third, under the all-or-nothing model, founders set a funding goal and keep nothing unless this goal is achieved (Cumming et al., 2014). All German equity crowdfunding portals operate under this all-or-nothing model. Nevertheless, they also allow the crowd to over-subscribe the issue up to a funding limit. Frequently, the funding goal has been set at 50,000 EUR. If this amount cannot be raised within a pre-specified period, the capital pledged is given back to the investors. Moreover, most German equity crowdfunding portals operating an all-or-nothing model allocate securities on an FCFS basis. Under this model, founders set an overall funding limit and stop selling securities to the crowd after the limit is reached. In the early years, the funding limit was often set at 100,000 EUR. After this threshold was reached, the funding process stopped before the pre-specified funding period came to an end, and investments were no longer sold to the crowd.

Innovestment has deviated from this model by implementing a three-stage, multi-unit second-price auction (Hornuf and Neuenkirch, 2017). After the start of the auction, investors can make pledges by specifying the number of tickets they want to buy and the price they are willing to pay for each ticket. In line with the other platforms, the portal and the startup determine a lower threshold for the price of a single ticket. During the first phase of the auction, everyone who pledges money is allotted the desired number of tickets, and the lowest posted price applies to everyone. Therefore, investors have no reason to outbid the lower threshold at this phase, unless they want to avoid the transaction cost of bidding again later.

The second phase of the auction starts when a pre-determined number of investment tickets have been allocated to the crowd. The number of tickets and, thus, the start of the second stage of the auction are not known to Innovestment investors until all tickets have been allocated. In this phase, the number of tickets is kept constant, and investors can outbid each other by posting higher prices. Importantly, the second phase is not restricted to investors from the first phase. Everyone who is registered on the portal can still join the bidding process. The second phase continuous until the funding limit is reached. For most campaigns on Innovestment, the funding limit was 100,000 EUR. The third and last phase of the auction starts as soon as the pre-determined funding limit is reached. During this phase, investors can still outbid one another. At this point, however, it is no longer possible to increase the overall sum of funds. Higher bids therefore result in the overall number of tickets being reduced, thus lowering the number of investments a startup must sell for a given amount of capital. ${ }^{3}$

In practice, one should bear in mind that only a few campaigns reached the third phase of the auction, while all other campaigns ended before the third or even second phase was reached. Moreover, while the auction mechanism was developed by an academic with the aim to design an optimal auction, the crowd might struggle to fully understand the mechanism. ${ }^{4}$ What should be clear to the crowd is that the different phases of the auction mechanism have no hard-ending rule, as everyone can still invest at each phase of the auction until the pre-determined duration of the funding cycle ends. Thus, unlike under the FCFS mechanism, in which it might merely be risky for the crowd to postpone an investment decision, investors might bid late under the auction mechanism, which could ultimately drive up the price per share. However, over-bidding can only occur in the second and third phases of the auction.

\section{Hypotheses}

Scholars have offered various explanations of what determines an individual investment decision. In this study, we test some of the most prevalent theories for the equity crowdfunding market in light of the portal designs that were implemented in practice.

\subsection{Allocation mechanism}

According to Fama (1965), in an efficient capital market it is fundamental information that determines the value of a security at every point in time. If investors lack knowledge of the fundamental value of an entrepreneurial firm, they may follow a naive portfolio diversification strategy such as $1 / \mathrm{N}$ or abstain from buying securities altogether. The first time the crowd learns about the venture is before an equity crowdfunding campaign even starts. All four equity crowdfunding portals require a business plan-including a financial forecast-available to potential investors. The information is open to all users of the portal before and during the investment process, which gives investors enough time to review the material before the campaign starts. In principle, the disclosure of the business plan should not affect the dynamics of the funding process later on. ${ }^{5}$ If anything, we would expect more investments in the early days of the funding cycle based on this information, leading to an L-shaped investment pattern.

Research on consumer behavior in the digital economy confirms such an investment pattern, stressing that information on the Internet is so plentiful that attention becomes limited over time (Wu and Huberman, 2007; Hodas and Lerman, 2013). It has therefore been hypothesized that attention in large groups follows an L-shape pattern. This is because attention to news first

\footnotetext{
3 The second phase of the auction was merged by the platform with the third phase from November 1, 2012 onwards, which led to a simplification of the auction mechanism. Consequently, the first phase continued until the funding limit was reached. Immediately thereafter, the third phase started. This modification did not affect the principal nature of the auction though.

4 Innovestment recently abolished the auction mechanism in favor of an FCFS model, as operated by all other German equity crowdfunding portals. However, our sample only covers campaigns run under the auction mechanism.

5 Becoming a user takes only a few minutes and requires potential investors to register with the portal. Hornuf and Schwienbacher (2017a) find that business plan length affects neither the amount raised in a campaign nor the intensity of crowd participation.
} 
increases as soon as some people attend to the information and pass it on to others. In equity crowdfunding, the initial attention to a campaign is reinforced by advertising campaigns and newsletters sent to potential investors by the portal before the campaign starts. Second, the news about a new campaign decays over time, resulting in fewer investments being made, a phenomenon also referred to as "collective attention effect" in the context of crowdfunding (Kuppuswamy and Bayus, 2017).

As the portals under consideration provide a primary market only and organized trading is not possible after the issuance of shares, an end-of-campaign effect may arise because no further trading takes place when the equity crowdfunding campaign is over (in contrast with an initial public offering, in which trading continues on the stock market). A well-known phenomenon in Internet auctions is late bidding, often referred to as "sniping" (Ariely et al., 2005). While under an FCFS mechanism late bidding may occur because of conformity and imitation (Bikhchandani et al., 1992; Roth and Ockenfels, 2002), under an auction it most likely results from bidders changing their evaluations of the startup in response to the information in others' bids. Investors might therefore want to bid late to avoid conveying information to the crowd. As a result, everyone tries to bid late in an auction with a hard-ending rule. By contrast, the crowd does not post a price on an investment ticket under the FCFS funding mechanism, as the price is set at the start of the campaign and does not change thereafter. Thus, there is no reason for investors to hold out to avoid a price surge under an FCFS mechanism and risk the campaign being sold out.

If sniping occurs in equity crowdfunding, it likely does so during the multi-unit second-price Innovestment auction outlined in Section 2.2. After all, if there is excessive demand for investments in the startup, bidding early might lead to a bidding war among investors, which ultimately drives up the price per ticket that is known to all investors. However, such a bidding war will most likely occur during the second and third phases of the auction or by the end of the funding period, as investors can join the auction at any point, making early investments and the associated disclosure of information via a bid unnecessary. Considering the combined impact of the collective attention effect and late bidding, we expect investment dynamics to be $U$ shaped under an auction mechanism rather than L shaped. Moreover, late bidding should be weak (if any) under the FCFS mechanism.

H1. Investment dynamics under an FCFS mechanism follow an L-shaped pattern. Late bidding is more likely to occur under an auction, leading to U-shaped funding dynamics.

Furthermore, as equity crowdfunding campaigns are only successful if a certain minimum funding threshold is reached, the funding dynamics might change when this point is surpassed. Reaching the minimum funding goal might provide evidence to potential investors that a critical mass of investors believes in the startup. In addition, according to Cumming et al. (2014), crowd investors face a much lower risk when the minimum funding goal is reached, because the entrepreneurial firm is less likely to be underfunded. This lower risk may induce more crowd investors to pledge their funds.

H2. Investments accelerate after the minimum funding goal is reached.

\subsection{Information provision}

The traditional finance literature (Fama, 1965; Ball and Brown, 1968; Fama et al., 1969; Scholes, 1969) predicts that if material information leaks to the market, investors immediately update their assessment of firm value and begin buying securities as soon as the information is disclosed. ${ }^{6}$ After the funding period has started and the venture accepts pledges from investors, investors can continue to learn more about the startup because the portal, in cooperation with the startup, may post updates on the portal website. Such updates might be considered a trustworthy source of information because they come from the startup itself. Block et al. (2017) argue that startups that release updates about funding events, business developments, and cooperation projects provide valuable information about their quality. Of course, the crowd can also learn about the startup from any other online or offline media source. The evidence shows, however, that portals quickly react to any relevant public information to promote the startup or to avert damage from the current campaign. ${ }^{7}$ Thus, information updates on the portal website should be the main source of information for investors.

H3. Posting information updates on the portal website increases investor participation.

In a survey by NESTA (2014), 69\% of the investors engaging in crowdlending stated that comments by other investors are important or very important regarding their own investment decisions. The information provided by other investors can be valuable for multiple reasons. First, the investor may provide information on how to improve the product, how to access more customers, or how to extend the business concept to another market. Second, the investor may offer personal help, which can range from distributing a leaflet to providing legal advice. Third, the investor may comment that he or she has already tried the product or service and offer evidence of its efficiency. Fourth, the investor may claim to know the market or to have experience in the industry, providing evidence of the viability of the business concept. Fifth, the investor may indicate that he or she is making another investment in the same firm, showing confidence in the investment overall. Committing more money might be a sign of a

\footnotetext{
${ }^{6}$ In recent years, the behavioral finance literature has contested this view. Ben-Shahar and Schneider (2014), for example, claim that the disclosure individuals need to deal with on a daily basis is already so extensive that they cannot read or react to all the information presented to them.

7 See, for example, the speculations that the startup Larovo is allegedly insolvent, which was quickly acted on by the portal Seedmatch: http://blog.seedmatch.de/ 2014/03/11/spekulationen-zu-larovo-ein-statement/.
} 
good relationship with the founder team and indicate positive investor relations. These comments might potentially affect investment decisions.

The only portal that does not allow comments by investors is Innovestment, because it operates a sealed-bid auction mechanism, in which investors observe the overall progress of the funding process but do not see individual investment decisions or comments by other investors. Burtch et al. (2015) find that information controls induce an increase in fundraising, because backers are more willing to engage with the platform, while decreasing the average contribution. They explain this result with a publicity effect, according to which backers respond to a lack of privacy by lowering extreme contributions. As anyone can use a fake user name and there is no way to privately contact an investor via the platforms under consideration in our study, we do not worry about the privacy concerns of investors. Thus, we hypothesize that investors take the information provided by other investors into account when making an investment decision, but abstract from privacy issues.

H4. Positive comments of previous investors increase follow-up investor participation.

\subsection{Investment behavior by others}

In the spirit of Spence (1973), investors might not regard information posted by other investors as credible. After all, investors who already decided to invest might not provide a balanced view, as they may suffer from confirmation bias (Chapman and Johnson, 2002) and therefore ex post justify their investment decisions. By contrast, potential investors might infer new information from the actual behavior of their peers. Business angels and other more sophisticated investors have more experience and might examine the startup more intensely by directly contacting the founders. These investors naturally invest larger amounts, which in turn makes a more thorough due diligence economically worthwhile. In this case, the crowd might update the perceived value of the venture from the investment behavior of others, especially if those investments are large. Finally, the crowd might act not only on the investment decisions of others but also on their disinvestment decisions, as portals provide a right to investors to withdraw their pledges within a two-week period after making an investment. ${ }^{8}$

H5a. Investor participation increases when investors observe a large investment.

H5b. Investor participation decreases when investors observe withdrawals.

\section{Data and methods}

\subsection{Data}

We use data from four German equity crowdfunding portals from November 6, 2011, till August 28, 2014. The portals we consider in our analysis represent four-fifths of the German equity crowdfunding market in terms of funding volume and number of startups being financed. For Companisto and United Equity, we were able to collect all investment decisions from the portal websites for all their campaigns. The data collection for Seedmatch and Innovestment was more difficult, as these portals take investment decisions off their website as soon as the funding limit is reached. Innovestment provided us with the complete investor data for all its successful (28) and unsuccessful (17) campaigns. Finally, we hand-collected investor data for 15 of 65 Seedmatch campaigns.

In total, we were able to collect investor data for 89 funding campaigns, which were run by 81 startups. BeECO (Innovestment), Ludufactur (Innovestment/Companisto), Meine-Spielzeugkiste (Companisto), Payme (Seedmatch), PlugSurfing (Innovestment), and swabr (Innovestment/Companisto) ran multiple campaigns, sometimes on different portals (as indicated in parentheses). Ledora (Seedmatch) and Protonet (Seedmatch) rapidly reached the funding limit and decided to raise more capital in a second round that quickly followed the first round. We counted these rounds as distinct campaigns, as investors could not know ex ante that a second round would follow a few days after the first round ended and thus did not adapt their investment behavior accordingly. Overall, investors funding these campaigns made 26,967 investment decisions in 89 distinct campaigns and provided 18.7 million EUR. Finally, 71,750 EUR was withdrawn after 57 investments were made.

From these data, we construct a panel dataset by aggregating the number of investments made in a particular campaign on a single day. Thus, our unit of observation is the number of investments for a given campaign day, with a specific campaign as the cross-sectional dimension and the day as the time dimension. For each campaign, we have as many observations as the duration in days of the campaign, which varies from one campaign to another because many campaigns achieve their limit before the end.

Table 1 provides summary statistics for the types of campaigns included in our sample. We provide summary statistics on the panel dataset in Section 5. Overall, $81 \%$ of the 89 campaigns achieved their minimum goal. More specifically, all portals except Innovestment were able to complete $100 \%$ of the campaigns successfully. With a high minimum investment ticket (in most cases, 1000 EUR), which represents a self-imposed restriction on capital supply, only two-thirds of the campaigns were completed successfully on Innovestment. This comparably lower success rate could also be due to Innovestment campaigns having defined a

\footnotetext{
${ }^{8}$ Such withdrawal rights are now legally guaranteed in Germany under the Small Investor Protection Act (Kleinanlegerschutzgesetz) (Klöhn et al., 2015). Similar rights apply in some other European countries.
} 
Table 1

Summary statistics: campaign-level data.

This table shows summary statistics of the 89 equity crowdfunding campaigns included in our sample. The dummy variable Funded (1 = Yes) indicates whether the campaign was successful; i.e., whether the funding goal was achieved. The variable Funding Goal gives the minimum amount of money (in EUR) below which the campaign is unsuccessful and thus no securities are issued. Funding Limit is the maximum amount (in EUR) the entrepreneur is willing to raise and set at the start of the campaign. The variable Total Amount Pledged gives the amount of money (in EUR) pledged during the duration of the campaign. Second Round (1 = Yes) is a dummy variable for whether the campaign is a second round of crowd financing; i.e., whether the entrepreneurial firm has already successfully raised equity crowdfunding in the past either on the same portal or another. Duration gives the time length in days of the campaign. It is the actual length of time, not the maximum duration set by the entrepreneur at the start of the campaign. Number of Backers gives the total number of crowd investors that pledged money during the campaign. Legal Form $(1=$ Private $L L C)$ is a dummy variable to indicate whether the entrepreneurial firm is structured as a private LLC. Security Type ( 1 = profit-part. loan) is a dummy variable indicating whether the security type offered to crowd investors is a profit-participating loan. Location of the Firm Berlin (1 = Yes) indicated whether the entrepreneurial firm is located in Berlin.

\begin{tabular}{|c|c|c|c|c|c|c|c|c|}
\hline & Mean & Median & Min. & Max. & Companisto & Innovestment & Seedmatch & United Equity \\
\hline & & & & & (Mean) & (Mean) & (Mean) & (Mean) \\
\hline Funded ( 1 = yes $)$ & 0.81 & 1 & 0 & 1 & 1.00 & 0.62 & 1.00 & 1.00 \\
\hline Funding goal $(€)$ & 51,687 & 50,000 & 15,000 & 150,000 & 30,555 & 60,747 & 66,667 & 20,000 \\
\hline Funding limit $(€)$ & 216,742 & 100,000 & 50,000 & $1,500,000$ & 238,704 & 108,556 & 520,000 & 80,000 \\
\hline Total amount pledged $(€)$ & 191,135 & 96,000 & 1500 & $1,500,000$ & 221,284 & 60,805 & 544,550 & 65,950 \\
\hline Second round ( $1=$ yes $)$ & 0.09 & 0 & 0 & 1 & 0.04 & 0.09 & 0.20 & 0.00 \\
\hline Duration (days) & 45 & 36 & 1 & 126 & 61 & 32 & 52 & 66 \\
\hline Number of backers & 293 & 48 & 1 & 1982 & 657 & 20 & 489 & 42 \\
\hline Legal form ( 1 = private LLC) & 0.83 & 1 & 0 & 1 & 0.81 & 0.78 & 1 & 1 \\
\hline Security type ( $1=$ part. Darlehen $)$ & 0.38 & 0 & 0 & 1 & 0.70 & 0.00 & 1 & 0 \\
\hline Location of the Firm Berlin ( $1=$ yes) & 0.45 & 0 & 0 & 1 & 0.81 & 0.36 & 0.13 & 0 \\
\hline No. Obs. & 89 & 89 & 89 & 89 & 27 & 45 & 15 & 2 \\
\hline
\end{tabular}

relatively high minimum funding threshold of 60,747 EUR on average, which is twice as high as that on Companisto. These higher thresholds might have a positive effect on campaign selection, which is beyond the scope of this article.

Table 1 further indicates that the average funding goal is 51,687 EUR (median of 50,000 EUR) and the average funding limit is 216,742 EUR (median of 100,000 EUR). However, our data also vary greatly, as the largest funding limit is 1.5 million EUR. The average campaign duration is 45 days (median of 36 days), and the average number of backers is 293 (median of 48). One campaign attracted 1982 backers. Adopting profit-participating loans as a standard investment contract legally allowed Seedmatch and Companisto to raise much larger amounts per campaign (Hornuf and Schwienbacher, 2017a, 2017b). As a result, the funding limit on Seedmatch was five times higher as that on Innovestment, and the total amount pledged by investors was higher as well. Moreover, because the minimum investment tickets on Seedmatch (250 EUR), United Equity (100 EUR), and, in particular, Companisto (5 EUR) were much lower than those on Innovestment (in most cases, 1000 EUR, but sometimes even 10,000 EUR or 25,000 EUR), more backers could join a single investment campaign. The maximum number of backers investing in a single campaign on Innovestment was 55, while on Companisto it was 1982.

In general, startups funded on Companisto, Seedmatch, and Innovestment were young and, on average, established in 2011. United Equity funded a construction firm that was established in 1979. Almost all firms in the sample were incorporated as a traditional LLC (the so-called GmbH), which requires a minimum legal capital of 25,000 EUR, 12,500 EUR of which must be put down at the time of incorporation. Some firms used the little sister of the $\mathrm{GmbH}$, the so-called Unternehmergesellschaft (haftungsbeschränkt), which emerged because of regulatory competition in Europe and requires a legal capital of only 1 EUR. Although the place of business is generally diverse for the campaigns under consideration, we find that most of the Companisto startups are based in Berlin, where the portal has its headquarter.

\subsection{Key explanatory variables}

To test our hypotheses, we construct several variables. Appendix Table 1 provides the definitions of these variables.

To account for the collective attention effect and allocation mechanism, we included dummy variables for the first and last seven days of the campaign, in line with Kuppuswamy and Bayus (2017). If a collective attention effect were prevalent in equity crowdfunding, we would expect the first days of the campaign to attract more investments in general. Furthermore, in case the collective attention is the only force influencing funding dynamics, the initial surge in investments should decay over time, and no further rise should take place during the last days of the funding period. This L-shaped dynamic should particularly hold for the portals running an FCFS mechanism. By contrast, if investors engage in late bidding under the auction mechanism, the dummy variables for the last day of the campaign should be positive and statistically significant. Furthermore, H1 comes into play when the first and the last days of the campaign dummies are jointly significant for the auction mechanism. As control variables, we calculate the variable Active Campaigns, which gives the number of projects across all four portals that accept investments on the same day, and the variable Competing Investments, for which we calculate the total number of investments run on a single day across all competing campaigns on all portals included in our sample. These two variables control for a potential "Blockbuster Effect" (Kickstarter, 2012), in which one campaign with many investors steals potential backers from other campaigns.

To test H2, we define a dummy variable called Post Funded as equaling 1 when the funding goal is achieved and 0 otherwise. Thus, if Post Funded $=1$, the entrepreneur can be certain to receive funding. Similarly, to investigate end-of-campaign effects 
under different allocation mechanisms, we construct two extra dummy variables, 90\%-Limit and 95\%-Limit, which equal 1 when all the pledges for a given campaign have reached $90 \%$ and $95 \%$ of the funding limit, respectively. For example, the dummy $90 \%$-Limit equals 1 for a campaign with a funding limit of 200,000 EUR if backers have pledged 180,000 EUR or more. Both these dummy variables capture end-of-campaign effects. In the empirical analysis, we consider these two variables separately rather than jointly, as they are highly correlated. Using them separately allows testing for robustness of our definition.

For information disclosure ( $\mathrm{H} 3$ and $\mathrm{H} 4$ ), we use several measures. One is the variable Update (lag 1) (Update (lag 1-7)), which measures the number of updates posted by entrepreneurs one day before (the last seven days before) the current day of the campaign. In the same vein, we construct similar count variables Comment (lag 1) and Comment (lag 1-7) for the number of comments posted by previous investors. To investigate in more detail the information content of past comments, we read each comment and categorize it into the following topics: whether the comment includes valuable information for product and/or market development, whether the investor offers personal help, whether the investor claims to already know the product, whether the investor claims to be an expert, and whether the investor says he or she is investing a second time (see Appendix Table 2 for a precise definition of the variable coding and examples of the respective comments). All these variables are again lagged one day in our analysis. To ensure reliability, two researchers made this categorization independently, and a third double-checked the categorizations when they differed between the first two researchers. Finally, we construct the variable Comment Length (lag 1), which gives the average length in number of letters of previously made comments, where "no comment" equals 0.

To test for peer investment effects (H5a), we construct dummy variables for lagged investments of a certain minimum size. This allows us to test whether investors base their decisions on the observed investment behavior of other investors. The variable Invest5k (lag 1) (Invest10k (lag 1)) gives the number of investments that have an amount of at least 5000 EUR (10,000 EUR) one day before the current day of a given campaign. Similarly, the variable Invest5k (lag 1-7) (Invest10k (lag 1-7)) gives the number of investments that have an amount of at least 5000 EUR (10,000 EUR) during the last seven days of a campaign. We further construct similar measures for withdrawals, which we denote as Withdrawals (lag 1) and Withdrawals (lag 1-1) (H5b).

\subsection{Empirical methods}

To identify the drivers of investment decisions, we examine the number of investments in an equity crowdfunding campaign on a given day. Because our dependent variable consists of count data, we begin with a Poisson regression model. As the unconditional variance of the dependent variable is larger than its mean, the Poisson model would suffer from over-dispersion, so we reject it in favor of a negative binomial model. As we observe no equity crowdfunding activities on $29 \%$ of the investment cycle days, we begin with a zero-inflated negative binomial (ZINB) model. No investment inactivity might be a function of certain characteristics of the equity crowdfunding portal, such as the number of users registered on the portal, the number of projects currently active on other equity crowdfunding portals, and so on. Running a Vuong (1989) test, we find that these and other predictors cannot explain a separate process for the count values and the excess zeros. Thus, we favor the standard negative binomial model over the ZINB model.

Our data are available for every day of the investment cycle, so we use a panel data model that takes into account the crosssectional and time-dependent nature of our aggregated data. Conducting a Hausman test leads us to dismiss the random-effects model as being inconsistent. We therefore adopted a fixed-effects negative binomial (FENB) estimator. The FENB model has the advantage of removing any unobserved, time-invariant heterogeneity for equity crowdfunding campaigns. For example, differences in the size of the minimum investment tickets, type of financial security, or specific clauses in the securities contracts will be differenced out. Because the FENB estimator, as suggested by Hausman et al. (1984), is a pseudo-panel estimator, the model permits the identification of time-invariant variables other than the unobserved campaign fixed effects, such as the number of patents held by the startup.

Finally, we included dummy variables to account for unobserved, time-variant heterogeneity. First, we include year dummies to control for the surging popularity of equity crowdfunding in recent years. Second, we include dummies for the month of the year. For example, during summertime, investors might have different opportunity costs, for example, when taking vacations or potentially having no access to the Internet. Third, we include dummies for weekdays, as investors might not be willing to spend their time investing on weekends in lieu of, for example, doing the shopping or spending time with their families. ${ }^{9}$

In taking our hypotheses and statistical considerations into account, we specify the following baseline equation:

$$
\begin{aligned}
& \operatorname{Pr}\left(\mathrm{y}_{\mathrm{i} 1}, \mathrm{y}_{\mathrm{i} 2}, \ldots, \mathrm{y}_{\mathrm{iT}}\right)=\mathrm{F}\left(\text { DoIC }_{\mathrm{it}}+\text { Active Campaigns }_{\mathrm{t}}+\text { Competing Investments }_{\mathrm{t}}+\text { Post Funded }_{\mathrm{it}}+\text { Patents }_{\mathrm{i}}+\text { Directors }_{\mathrm{i}}\right. \\
& \left.+ \text { DoW }_{\mathrm{t}}+\text { MoY }_{\mathrm{t}}+\text { Year }_{\mathrm{t}}+\text { Campaign }_{\mathrm{i}}\right) \text {, }
\end{aligned}
$$

where $y$ is the number of investments in campaign $i$ on day $t$ of the investment cycle, $F($.$) denotes a negative binomial distribu-$ tion function as in Baltagi (2008), DoIC is a vector of dummies indicating the first and last seven days of the investment cycle as in Kuppuswamy and Bayus (2017), Active Campaigns $\mathrm{t}_{\mathrm{t}}$ represent the number of startups across all portals that accept pledges on day $\mathrm{t}$, and Competing Investments $\mathrm{t}_{\mathrm{t}}$ are the maximum number of cumulative investments across all competing projects being pledged on day t. In every specification, we include a measure of innovativeness of the startup ( $\mathrm{Nbr}$. Patents) and a measure of development and human capital of the startup (Nbr. Directors). These two variables are time-invariant within each campaign.

\footnotetext{
${ }^{9}$ Shops are generally closed on Sundays, and opening hours are shorter on Saturdays in Germany.
} 
Furthermore, DoW is a vector of dummies indicating the day of the week, MoY is a vector of dummies for the month of the year, and Year is a vector of dummies for years from 2012 onward, excluding 2011. Finally, Campaign $n_{\mathrm{i}}$ captures the campaign fixed effects.

As our panel data has a time component, it is natural to question whether stationarity could be an issue. Although to the best of our knowledge no formal tests exist for the estimation methodology used here, we checked for unit roots in a linear model (using the command "xtunitroot" in STATA). While some unit-root tests require a strongly balanced dataset, others can be performed with any structure. This is also the case for the Fisher-type test for panel data, which is the test most closely linked to the traditional augmented Dickey-Fuller unit-root test for standard time series. We also checked other tests; all rejected the null hypothesis that all the time series in the panel contain a unit root.

\section{Results}

\subsection{Descriptive statistics}

Table 2, Panel A, provides summary statistics for the 4027 campaign-day observations. In our sample, an entrepreneurial firm obtains on average 6.7 investments per day, amounting to 4623 EUR. The median is smaller, with 2 investments per day and 650 EUR. This result reflects the skewness of the distribution of the dependent variable, which follows a negative binomial-type distribution. Moreover, 0.2 investments per day are 5000 EUR or higher, suggesting that such larger investments by a single investor are rather rare. By contrast, withdrawals during the funding period are infrequent because most withdrawals take place after the campaign is closed and are not part of our analysis. On average, 5.9 projects are proposed on the four portals on a given campaign day to crowdinvestors (Active Campaigns). Panel B provides means of the different variables for each portal separately and highlights great variation across portals, with the most daily activities on Companisto and Seedmatch.

Regarding the distribution of campaign outcomes, we find that almost all campaigns run on Companisto, Seedmatch, and United Equity reached $>200 \%$ of their funding goal. However, there is also strong variation across portals (Fig. 1 ).

Table 2

Summary statistics of panel data.

This table shows summary statistics of main variables for our panel data set (campaign-day observations). Panel A shows statistics for the full sample of 4027 campaignday observations. Panel B shows statistics for each portal separately. All the variables are defined in Appendix Table 1.

\begin{tabular}{|c|c|c|c|c|c|c|c|c|}
\hline \multicolumn{9}{|l|}{ Panel A: full sample } \\
\hline Variable & Mean & Median & Std. Dev. (overall) & Std. Dev. (between) & Std. Dev. (within) & Min & Max & No. obs. \\
\hline Investments & 6.70 & 2 & 27.70 & 120.6 & 17.70 & 0 & 1107 & 4027 \\
\hline Amount (EUR) & 4623 & 650 & 32,403 & 163,387 & 16,917 & -1250 & $1,499,750$ & 4027 \\
\hline Duration (days) & 63.88 & 59 & 33.25 & 29.97 & 0 & 0 & 125 & 4027 \\
\hline Post funded ( $1=$ yes $)$ & 0.662 & 1 & 0.473 & 0.437 & 0.254 & 0 & 1 & 4027 \\
\hline Funding goal (EUR) & 46,976 & 50,000 & 22,794 & 24,663 & 0 & 15,000 & 150,000 & 4006 \\
\hline Auction $(1=$ yes $)$ & 0.36 & 0 & 0.48 & 0.50 & 0 & 0 & 1 & 4027 \\
\hline Updates & 0.04 & 0 & 0.23 & 0.09 & 0.22 & 0 & 2 & 4027 \\
\hline Invest10k & 0.06 & 0 & 0.69 & 2.53 & 0.47 & 0 & 32 & 4027 \\
\hline Invest5k & 0.2 & 0 & 1.87 & 10.09 & 0.87 & 0 & 93 & 4027 \\
\hline Withdrawals & 0.014 & 0 & 0.300 & 0.518 & 0.237 & 0 & 15 & 4027 \\
\hline Nbr. patents & 0.156 & 0 & 0.585 & 0.948 & 0 & 0 & 7 & 4027 \\
\hline Nbr. directors & 2.035 & 2 & 1.187 & 1.158 & 0 & 1 & 6 & 4027 \\
\hline Active campaigns & 5.85 & 5 & 2.96 & 2.56 & 1.5 & 1 & 12 & 4027 \\
\hline Competing investments & 36.04 & 21 & 59.33 & 119.74 & 53.76 & 0 & 1122 & 4027 \\
\hline Panel B: by portal for eac & ortal se & ately (only & neans are reported) & & & & & \\
\hline Variable & & Compani & & Seedmatch & United Equ & & & vestment \\
\hline Investments & & 10.67 & & 9.69 & 0.64 & & & \\
\hline Amount $(€)$ & & 3584 & & 10,360 & 469 & & & \\
\hline Duration (days) & & 79.63 & & 82.49 & 66.23 & & & \\
\hline Post funded (D) & & 0.926 & & 0.940 & 0.189 & & & \\
\hline Goal $(€)$ & & 29,882 & & 59,744 & 19,318 & & & 46 \\
\hline Auction (D) & & 0.00 & & 0.00 & 0.00 & & & \\
\hline Updates & & 0.09 & & 0.00 & 0.00 & & & \\
\hline Invest25k (D) & & 0.004 & & 0.000 & 0.000 & & & \\
\hline Invest10k (D) & & 0.038 & & 0.15 & 0.00 & & & \\
\hline Invest5k (D) & & 0.13 & & 0.46 & 0.02 & & & \\
\hline Withdrawals & & 0.000 & & 0.073 & 0.000 & & & \\
\hline Nbr. patents & & 0.055 & & 0.546 & 0.000 & & & \\
\hline Nbr. directors & & 1.938 & & 2.251 & 3.432 & & & \\
\hline Active projects & & 5.13 & & 7.48 & 4.03 & & & \\
\hline Max comp. invest. & & 38.10 & & 52.39 & 16.94 & & & \\
\hline No. obs. & & 1659 & & 780 & 132 & & & \\
\hline
\end{tabular}


Overall

$(\mathrm{N}=89$ rounds, $\mathrm{n}=26,967$ investments)

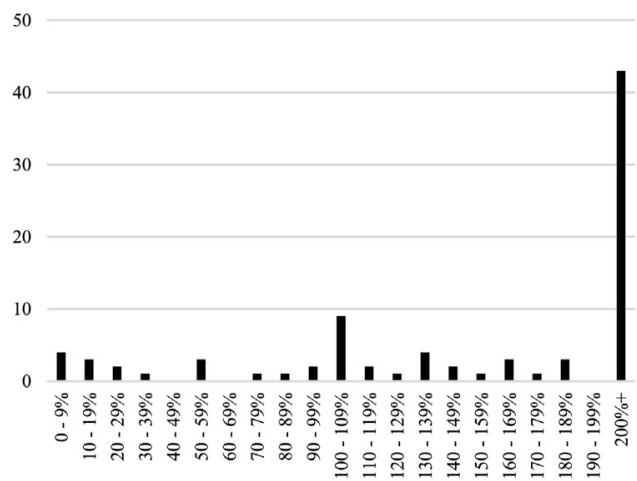

Companisto

( $\mathrm{N}=27$ rounds, $\mathrm{n}=17,694$ investments)

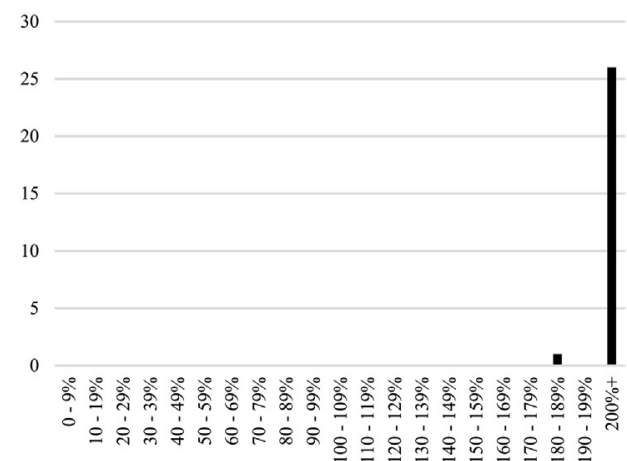

Innovestment

( $\mathrm{N}=45$ rounds, $\mathrm{n}=1,628$ investments)

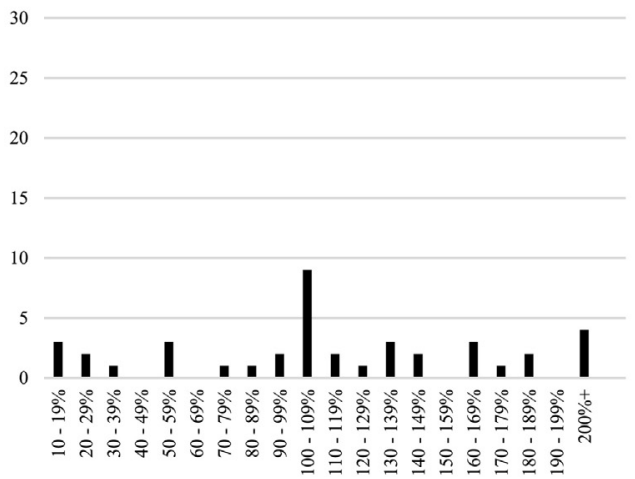

Seedmatch

( $\mathrm{N}=15$ rounds, $\mathrm{n}=5,761$ investments)
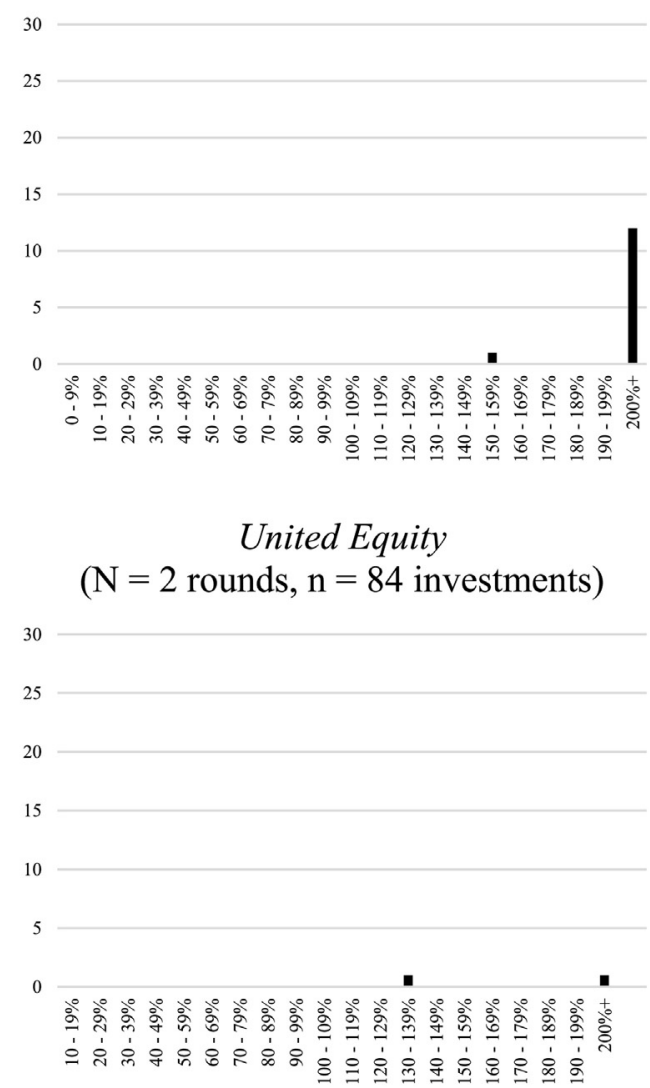

Fig. 1. Distribution of campaign outcomes.

Finally, regarding the dynamics of the funding cycle (Fig. 2), we find that the average number of investments is L shaped, providing initial support for the collective attention effect and H1. Moreover, the pattern of average capital invested is U shaped, indicating that the amount per investment was larger in the early and later phases of the investment cycle. This effect is the strongest for Innovestment, on which the number of investments is almost flat over the entire funding cycle. However, the average amount invested on Innovestment surges in the early days and especially in the end phase of the funding cycle. The strongest support for an L-shaped funding cycle and H1 comes from Companisto and Seedmatch, which mobilize most investors per campaign and follow the FCFS mechanism. The latecomer United Equity shows little activity over the entire funding cycle. 
L. Hornuf, A. Schwienbacher / Journal of Corporate Finance $x x x$ (2017) $x x x-x x x$

Average Number of Investments

Overall

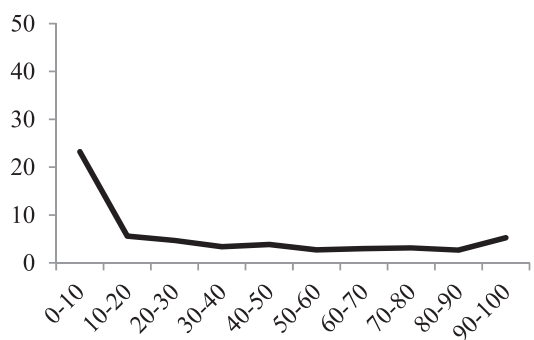

Companisto

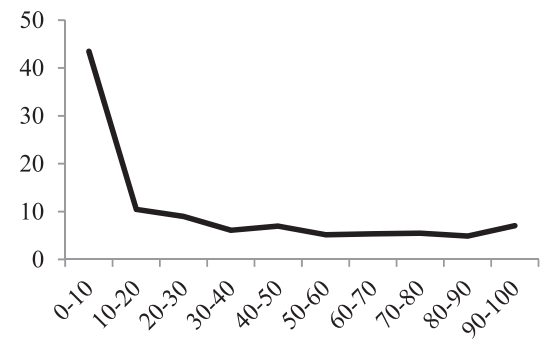

Innovestment

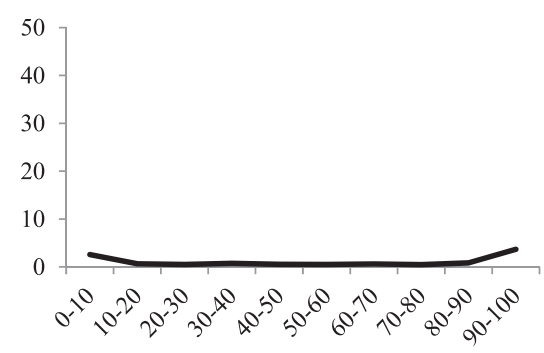

Seedmatch

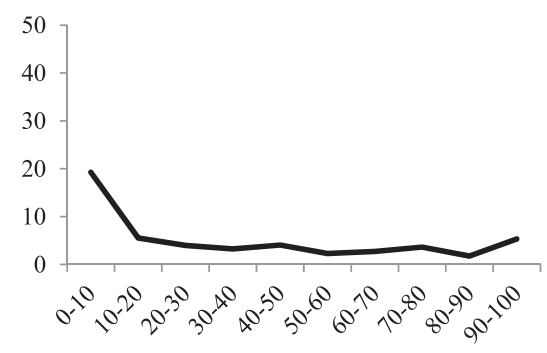

United Equity

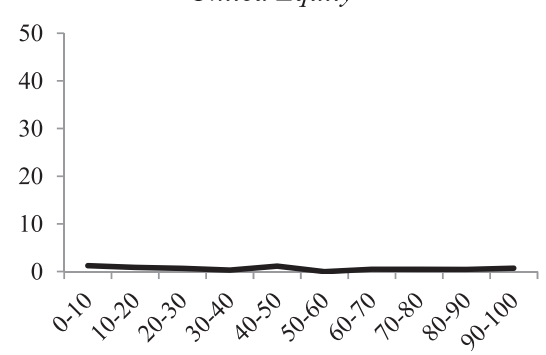

Percent of Investment Cycle Elapsed
Average Aggregate Investment per Day

Overall

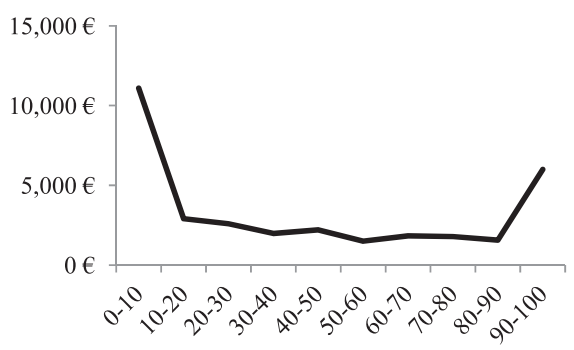

Companisto

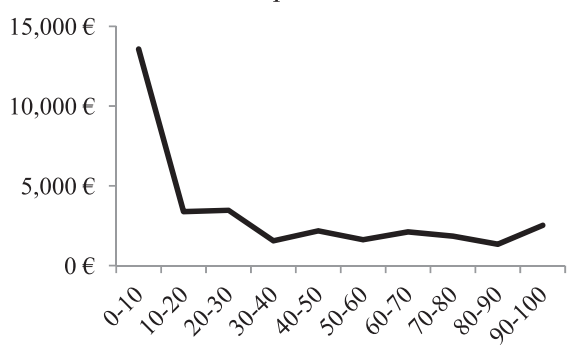

Innovestment

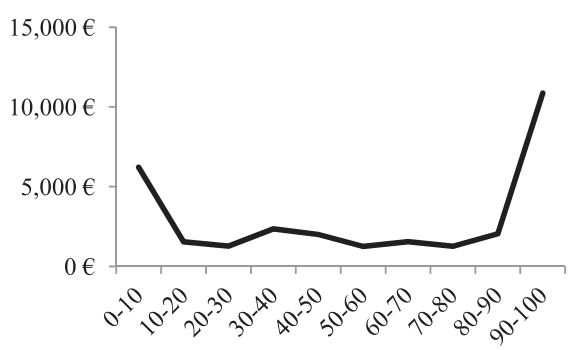

Seedmatch
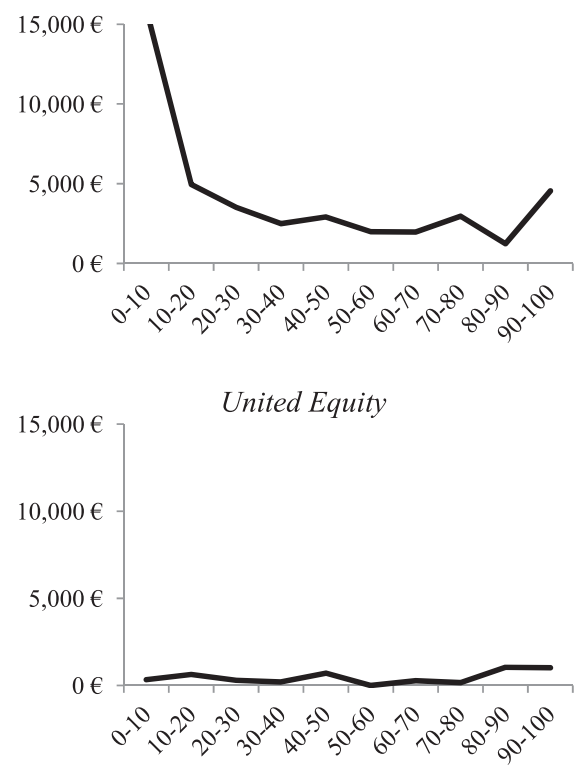

Percent of Investment Cycle Elapsed

Fig. 2. Average number of investments and average aggregate investment. The figures display funding rounds with a minimum of 10 campaign days. 
Table 3

Baseline regression on investment dynamics.

This table shows results of the baseline regressions, as specified in Section 4.3. Next to the variables reported in the table, this baseline regression also includes dummy variables for the day of the week, month of the year, and year dummies. All the variables reported below are defined in Appendix Table 1 . The dependent variable is the number of investments in a specific campaign and day. The first column shows results for the full sample of 4025 campaign-day observations, the second column for the sub-sample of campaigns running under the FCFS mechanism, and the third column under the auction mechanism. Coefficients reported are incidence rate ratios. Data take panel-data structure. The method of estimation is the panel-data Negative Binomial regression with fixed effects. The last three lines reports LR-test results of joint coefficient tests. Significance levels (for coefficient being different from 1 ): ${ }^{*}<10 \%,{ }^{* *}<5 \%,{ }^{* * *}<1 \%$.

\begin{tabular}{|c|c|c|c|}
\hline \multirow[t]{2}{*}{ Explanatory variables } & Full sample & FCFS mechanism & Auction mechanism \\
\hline & [1] & [2] & [3] \\
\hline 1st day & $14.728^{* * *}$ & $13.374^{* * *}$ & $10.406^{* * *}$ \\
\hline 2nd day & $6.532^{* * *}$ & $7.052^{* * *}$ & $3.204^{* * *}$ \\
\hline 3rd day & $3.920^{* * *}$ & $4.503^{* * *}$ & $1.807^{* * *}$ \\
\hline 4th day & $2.769^{* * *}$ & $3.082^{* * *}$ & $1.540^{*}$ \\
\hline 5 th day & $2.317^{* * *}$ & $2.586^{* * *}$ & 1.329 \\
\hline 6th day & $1.855^{* * *}$ & $2.126^{* * *}$ & 0.911 \\
\hline 7th day & $1.702^{* * *}$ & $1.902^{* * *}$ & 1.340 \\
\hline 7th last day & 1.036 & 1.085 & 1.273 \\
\hline 6th last day & $1.181^{*}$ & $1.192^{*}$ & 1.415 \\
\hline 5th last day & $1.207^{* *}$ & 1.102 & $1.727^{* * *}$ \\
\hline 4th last day & $1.269^{* * *}$ & 1.162 & $1.882^{* * *}$ \\
\hline 3rd last day & $1.762^{* * *}$ & $1.477^{* * *}$ & $2.650^{* * *}$ \\
\hline 2nd last day & $2.413^{* * *}$ & $1.892^{* * *}$ & $5.124^{* * *}$ \\
\hline Last day & $2.719^{* * *}$ & $1.448^{* * *}$ & $11.126^{* * *}$ \\
\hline Nbr. patents & 1.046 & 0.979 & 1.179 \\
\hline Nbr. directors & 1.040 & 0.967 & 0.725 \\
\hline Active campaigns & $1.022^{* *}$ & $1.031^{* * *}$ & 1.007 \\
\hline Competing investments & $1.002^{* * *}$ & $1.002^{* * *}$ & 1.001 \\
\hline Post funded & $1.510^{* * *}$ & 0.948 & $1.910^{* * *}$ \\
\hline Chi2 & $5866.22^{* * *}$ & 7948.91*** & $1071.42^{* * *}$ \\
\hline No obs. & 4025 & 2570 & 1455 \\
\hline Chi2 (all first days $=1$ ) & $3010.87^{* * *}$ & $2697.38^{* * *}$ & $403.08^{* * *}$ \\
\hline Chi2 (all last days $=1$ ) & $324.08^{* * *}$ & $76.30^{* * *}$ & $352.24^{* * *}$ \\
\hline Chi2 (all first and last days $=1$ ) & $3147.07^{* * *}$ & $2727.98^{* * *}$ & $718.12^{* * *}$ \\
\hline
\end{tabular}

In the rest of this section, we report the empirical results on the FENB models. First, we provide results on the baseline specification, which depicts the general pattern of investment dynamics. Second, we examine whether there is an end-of-campaign effect, while distinguishing between the two securities allocation mechanisms used by the four portals. Third, we explore the impact of peer investments and information originating from the entrepreneurial firm and other crowd investors.

\subsection{Baseline funding dynamics}

In Table 3, we present the results of the baseline FENB estimations for 4025 investment days on four German equity crowdfunding portals. ${ }^{10}$ We report incidence rate ratios, as they can conveniently be interpreted as a multiplicative effect or semi-elasticity. This implies that all estimates $<1$ must be interpreted as a negative effect, while estimates $>1$ reveal a positive relationship.

In line with Kuppuswamy and Bayus (2017), we find that investors are more likely to contribute in the first and last days of a campaign than in the middle phase of the funding cycle. Yet, as outlined in Section 5.1, most of the funding activity really takes place in the early phase of the funding cycle, which provides strong evidence of the collective attention effect and H1. In support of this, the incidence rate ratios on day 1 of the funding cycle are all above 14, while the incidence rate ratios on the last day of the funding cycle do not exceed 3. The last rows in Table 3 offer a formal test of H1, where we test whether the coefficients of the first days are also jointly different from 1. Even under the FCFS funding mechanism in Model (2), we find a small rise in investments during the last three days of the funding period. This effect might be due to some investors closely watching the funding dynamics and ultimately fearing that they will no longer be able to invest. Despite the brief surge in investments toward the end, which might be due to factors unrelated to the collective attention effect, we view the investment dynamics in equity crowdfunding as more L shaped than U shaped.

Model (3) shows similar regressions for the sub-sample of the auction mechanism. Comparison of the results of Models (2) and (3) provides evidence that the auction mechanism leads to a stronger end-of-campaign effect. Moreover, in line with H1, the collective attention effect and late bidding are not exclusive under an auction mechanism, as funding dynamics now clearly resemble a $\mathrm{U}$ shape. We examine this difference further in the next sub-section. Table 3 also shows results of likelihood-ratio

\footnotetext{
10 Our initial sample as reported in Table 2 contains 4027 observations. We drop two observations in the panel estimations because two campaigns lasted only one day and no time variation exists to identify the respective campaign effects. The dropped campaigns are "HeBePro" (Innovestment) and the first round of "Protonet" (Seedmatch).
} 
tests, in which we test whether the coefficients of the last seven days are jointly equal to 1 . In all the specifications, this test is rejected, providing support for an increase of investments at the end of the campaign.

Furthermore, we find no support for the notion of a Blockbuster Effect. By contrast, we find that more activity in general (Competing Investments) triggers more investments in a particular campaign. In line with this finding, we observe that the active campaigns themselves (Active Campaigns) have a small but positive effect on investments on a specific campaign day, which is also consistent with the collective attention effect of crowdfunding-namely, if more news is spread about equity crowdfunding in general. One possible reason for the lack of a Blockbuster Effect is that equity crowdfunding campaigns are not open-ended and there is a limit to the campaign size. Thus, individual campaigns cannot become as large to steal potential backers from other campaigns. This contrasts with Kickstarter, on which campaigns are typically open-ended and entrepreneurs can take as many pledges as they want.

Finally, entrepreneurs obtain more investments after the funding goal is reached (Post Funded), indicating that investors infer a positive signal when the threshold is surpassed. Compared with pre-funding, the number of investments is on average $51.0 \%$ larger in the post-funding period. This finding is mainly driven by the auction mechanism, as we do not observe a similar trend for the FCFS mechanism. Thus, we find mixed evidence for H2.

In what follows, we supplement this baseline specification with additional variables to shed further light on the funding dynamics and to test our hypotheses. The findings with regard to first days, the collective attention effect, and post-funding continue to hold. To conserve space, we do not report them again.

\section{Table 4}

End-of-campaign effect.

Next to the variables reported in the table, the regressions also include dummy variables for the first seven days of the campaign, day of the week, month of the year, and year dummies. All the variables reported below are defined in Appendix Table 1. The dependent variable is the number of investments in a specific campaign and day. Coefficients reported are incidence rate ratios. Data take panel-data structure. The method of estimation is the panel-data Negative Binomial regression with fixed effects. Significance levels (for coefficient being different from 1 ): ${ }^{*}<10 \%,{ }^{* *}<5 \%,{ }^{* * *}<1 \%$.

\begin{tabular}{|c|c|c|c|c|c|}
\hline \multicolumn{6}{|l|}{ Panel A: full sample } \\
\hline Explanatory variables & {$[1]$} & {$[2]$} & [3] & {$[4]$} & {$[5]$} \\
\hline Post funded & $1.689^{* * *}$ & & $1.692^{* * *}$ & & $1.691^{* * *}$ \\
\hline $90 \%$ - limit & & $1.176^{* * *}$ & $1.183^{* * *}$ & & \\
\hline 95\% - limit & & & & $1.158^{* * * *}$ & $1.165^{* * * *}$ \\
\hline Nbr. patents & $1.090^{* *}$ & 1.061 & $1.085^{* *}$ & 1.060 & $1.084^{* *}$ \\
\hline Nbr. directors & 0.979 & 1.014 & 0.976 & 1.013 & 0.976 \\
\hline Active projects & $1.021^{* *}$ & $1.022^{* *}$ & $1.017^{*}$ & $1.022^{* *}$ & $1.017^{*}$ \\
\hline Max comp. invest. & $1.002^{* * *}$ & $1.002^{* * *}$ & $1.002^{* * *}$ & $1.002^{* * *}$ & $1.002^{* * * *}$ \\
\hline Chi2 & 5150.23 & 4980.44 & 5227.49 & 4967.64 & 5210.53 \\
\hline No. obs. & 4025 & 4025 & 4025 & 4025 & 4025 \\
\hline
\end{tabular}

Panel B: sub-samples by types of mechanisms

\begin{tabular}{|c|c|c|c|c|c|c|c|c|}
\hline \multirow[t]{2}{*}{ Explanatory variables } & \multicolumn{4}{|c|}{ FCFS mechanism (all other portals) } & & \multicolumn{3}{|c|}{ Auction mechanism (Innovestment) } \\
\hline & [1] & \multicolumn{2}{|l|}{$[2]$} & \multicolumn{2}{|l|}{$[3]$} & {$[4]$} & {$[5]$} & {$[6]$} \\
\hline Post funded & 0.946 & 0.952 & & 0.944 & & $4.283^{* * *}$ & $3.972^{* * *}$ & $4.040^{* * *}$ \\
\hline $90 \%$ - limit & & 1.038 & & & & & $1.375^{* *}$ & \\
\hline 95\% - limit & & & & 0.981 & & & & $1.321^{* *}$ \\
\hline Nbr. patents & 0.996 & 0.995 & & 0.997 & & 0.901 & 0.951 & 0.944 \\
\hline Nbr. directors & 0.953 & 0.954 & & 0.953 & & 1.469 & 1.227 & 1.257 \\
\hline Active projects & $1.034^{* * *}$ & $1.034^{* *}$ & & $1.035^{* * *}$ & & 0.970 & 0.963 & 0.963 \\
\hline Max comp. invest. & $1.002^{* * *}$ & $1.002^{* * *}$ & & $1.002^{* * *}$ & & 1.002 & 1.002 & 1.002 \\
\hline Chi2 & 7584.20 & 7596.67 & & 7579.48 & & 438.29 & 439.78 & 439.23 \\
\hline No. obs. & 2570 & 2570 & & 2570 & & 1455 & 1455 & 1455 \\
\hline \multicolumn{9}{|c|}{ Panel C: including interaction terms } \\
\hline Explanatory variables & {$[1]$} & & {$[2]$} & & {$[3]$} & & {$[4]$} & {$[5]$} \\
\hline Post funded & $0.880^{* *}$ & & & & 1.050 & & & 1.054 \\
\hline $90 \%$ - limit & & & 1.006 & & 1.012 & & & \\
\hline 95\% - limit & & & & & & & 0.945 & 0.951 \\
\hline Auction & $0.098^{* * *}$ & & $0.118^{* * *}$ & & $0.122^{* * *}$ & & $0.121^{* * *}$ & $0.125^{* * *}$ \\
\hline Post funded $*$ auction & $4.471^{* * *}$ & & & & & & & \\
\hline $90 \%$ - limit $*$ auction & & & $3.034^{* * *}$ & & $2.947^{* * *}$ & & & \\
\hline $95 \%$ - limit $*$ auction & & & & & & & $3.145^{* * *}$ & $3.047^{* * *}$ \\
\hline Nbr. patents & 1.010 & & 1.017 & & 1.019 & & 1.021 & 1.023 \\
\hline Nbr. directors & 0.974 & & 0.960 & & 0.956 & & 0.956 & 0.953 \\
\hline Active projects & $1.028^{* * *}$ & & $1.016^{*}$ & & $1.016^{*}$ & & $1.016^{*}$ & $1.016^{*}$ \\
\hline Max comp. invest. & $1.002^{* * *}$ & & $1.002^{* * *}$ & & $1.002^{* * *}$ & & $1.002^{* * *}$ & $1.002^{* * *}$ \\
\hline Chi2 & 7394.91 & & 7071.45 & & 7066.74 & & 7022.19 & 7016.63 \\
\hline No. obs. & 4025 & & 4025 & & 4025 & & 4025 & 4025 \\
\hline
\end{tabular}




\subsection{Allocation mechanisms and end-of-campaign effect}

In this section, we test the end-of-campaign effect-that is, the funding dynamics when a campaign gets close to the funding limit as ex ante defined by the entrepreneur. The goal is to identify whether a run-up occurs as the campaign approaches this limit. The results appear in Table 4, in which we extend the baseline specification (we exclude the last-seven-day dummies to capture the end-of-campaign effect with our separate measures) with two extra variables: 90\%-Limit and 95\%-Limit. These two variables capture effects when the campaign approaches the funding limit, so only a few securities are not yet allotted. We further perform the analysis on the dummy variable Post Funded. In Panel A, we perform the analysis on the full sample. In Panel B, we run the regressions separately for campaigns using the FCFS and auction mechanisms. In Panel C, we again perform the analysis on the full sample but include interaction terms to more formally test H1. We expect these mechanisms to affect the end-of-campaign effect because an auction mechanism ensures that the campaign lasts until the end of the announced campaign duration. By contrast, the campaign may end prematurely under the FCFS mechanism, which could reduce the end-of-campaign effect as crowd investors may invest early on rather than wait until the end of the campaign. Waiting under the FCFS mechanism is risky because investors may no longer be able to invest.

Our results confirm this prediction. When considering the full sample (Panel A), we find a run-up as the campaign approaches the funding limit, such that the number of unallocated securities becomes low. However, as Panel B shows, this effect is only driven by campaigns run under the auction mechanism, which provides support for H1. Under the FCFS mechanism, there is no significant end-of-campaign effect, while the auction mechanism accelerates investments by $37.5 \%$ (32.1\%), as we achieve $90 \%$ (95\%) of the funding cycle. In Panel C, we offer a formal test for all three measures, PostFunded, 90\%-Limit, and 95\%-Limit, which we interact with the dummy variable Auction, which equals 1 for campaigns run under the auction mechanism. The incident rate ratios of the interaction effect are consistently above 1 and significantly different from 1, while the coefficients of the end-of-campaign measure are never significant. Taken together, these results indicate a strong end-of-campaign effect for the auction mechanism but no effect for the FCFS mechanism and thus provides empirical support for $\mathrm{H} 1$.

To ensure robustness of these conclusions, we performed two additional tests not reported in the tables. First, one difficulty in the identification strategy used here is that the Auction dummy is identical to an Innovestment dummy. Thus, other unobserved factors in portal design might drive our results. However, it is important to note that any such unobserved factors-next to the auction mechanism we identify-should not only be static (e.g., different contract characteristics, different website design) but also affect the dynamics of the funding process. Mere static factors only change the overall level of investor support and thus will be taken care of by the fixed-effect panel estimator used in our regressions. Moreover, if we were not considering an important unobserved factor, it is unlikely that this factor would be missing from all three portals running the FCFS mechanism, and we would then expect very different dynamics on Companisto, Seedmatch, and United Equity. In unreported analyses, we examined the end-of-campaign effect on Companisto and Seedmatch separately and did not find any effect for Companisto and, compared with the auction mechanism, a very weak effect for Seedmatch. After further inspection, we find that the effect on Seedmatch is largely driven by a few, very short campaigns. Excluding the campaigns that lasted fewer than five days leads to no end-of-campaign effect even for Seedmatch.

Second, a dynamic model may be more appropriate, for example, if information cascades occur from one day to another, in line with what Vismara (2017) finds for early and late investors. In this case, the inclusion of a lagged dependent variable seems adequate. However, none of the German portals we consider in our sample tie investor profiles to social media websites such as LinkedIn. Moreover, to the best of our knowledge, there is no consistent dynamic panel estimator for negative binomial regressions like the ArellanoBond estimator for traditional panel models. Finally, for the auction mechanism, we are likely to have opposing dynamics at the start and the end of campaign that would cancel each other out in a dynamic setting. At the start, we observe a downward movement (coefficients $<1$ ); at the end, there is a strong increase (coefficients $>1$ ). When including a lagged dependent variable, we simply obtain an average of the two opposing dynamics. Given these reasons, we do not report these estimations here, but note that the inclusion of a lagged dependent variable does not affect our results on the end-of-campaign effects.

\subsection{Effect of information disclosure (updates and comments)}

Next, we turn to examining the effect of information disclosure on funding dynamics. Different types of information are disclosed during the funding cycle of a campaign. Block et al. (2017) argue that updates may contain new information about

Table 5

Summary statistics on update and comment variables.

This table shows summary statistics on updates provided by the entrepreneur during the campaign and comments posted by crowd investors. All the variables reported below are defined in Appendix Table 1. Data take panel-data structure.

\begin{tabular}{lllll}
\hline Variable & No obs. & Sum & p95 & Maximum \\
\hline Update & 4025 & 154 & 0 & 0 \\
Comment & 4025 & 8638 & 6 & 0 \\
Valuable info & 4025 & 257 & 0 & 0 \\
Offers help & 4025 & 44 & 0 & 0 \\
Knows product & 4025 & 146 & 0 & 0 \\
Expert claim & 4025 & 217 & 0 & 0 \\
Second time & 4025 & - & 0 & 0 \\
Comment length & 4025 & 45.25 & 18 \\
\hline
\end{tabular}


the product or startup that was not available at the start of the campaign. The second type of information disclosed during the campaign comes from investors, who can post a personal comment at the time they make an investment. Although many of these comments are limited to a "good luck" statement, others may be valuable for the firm. As outlined in Section 4.2., we categorize comments into whether they contain information that is potentially valuable for product and/or market development (Valuable Info), whether the investor offers personal help to the entrepreneur (Offer Help), whether the investor claims to know the product already (Knows Product), whether the investor claims to be an expert (Expert Claim), or whether the investor says he or she is investing a second time in the same campaign (Second Time). As these claims are only made by investors and cannot be verified by others, such comments may just be cheap talk; whether they have an impact is an empirical question we aim to investigate.

Table 5 provides summary statistics on the information disclosure variables. Statistics are based on panel data (campaign-day observations). Updates are rarely posted, as evidenced by the value 0 at the $95 \%$ percentile of the variable Update. In total, only 154 updates were posted during the full sample of 89 campaigns. Conversely, comments are more frequent. In total, 8638 comments were posted, often with little information content beyond personal encouragement. In 257 cases, the comments included information that could potentially be valuable to the startup.

Table 6 shows the findings regarding the impact of updates and comments on the funding dynamics. Again, all the specifications include the baseline variables. Panel A shows results with the variables Updates and Comments (both variables lagged either 1 day or 1-7 days). Panel B presents findings based on the different types of comments. Finally, Panel $C$ introduces interaction terms between comment type (as in Panel B) and the dummy variable Post Funded, to investigate whether there is a differential impact when the campaign has already achieved the funding goal and therefore investments take place with certainty.

Consistent with prior research (Block et al., 2017), we find that posting updates by the entrepreneur increases subsequent investments, particularly on the next day when an update increases the number of investments by $17.7 \%$. Comments also have a positive and significant effect, but the economic impact is small. This may be because most comments are encouragement and thus have little economic value. Panel B of Table 6 therefore shows the impact of specific types of comments on the funding dynamics. We find that all types of comments have a positive and significant impact on the subsequent number of investments, with Offers Help having the largest economic impact, followed by Expert Claim, Valuable Info, Second Time, and, finally, Knows Product. When testing the impact of these different types of comments jointly (Regression (6)), we find that only three remain significant.

Table 6

Impact of update and comment variables on investment dynamics.

This table shows results of the baseline regressions, as specified in Section 4.3, amended by Updates and Comments variables. Next to the variables reported in the table, all the regressions include dummy variables for the first and last 7 days of campaigns, the day of the week, month of the year, and year dummies. All the variables reported below are defined in Appendix Table 1. In Panel C, we also include interaction terms by interacting each comment and update variable with the dummy variable Post Funded. In Panel C, each line corresponds a separate specification. The dependent variable is the number of investments in a specific campaign and day. Coefficients reported are incidence rate ratios. Data take panel-data structure. The method of estimation is the panel-data Negative Binomial regression with fixed effects. Significance levels (for coefficient being different from 1 ): ${ }^{*}<10 \%,{ }^{* *}<5 \%,{ }^{* * *}<1 \%$.

\begin{tabular}{|c|c|c|c|c|c|c|c|c|}
\hline \multicolumn{9}{|c|}{ Panel A: baseline regressions on updates and comments } \\
\hline Explanatory variables & & {$[1]$} & & {$[2]$} & & {$[3]$} & & {$[4]$} \\
\hline Update (lag 1) & & $1.177^{* * *}$ & & & & & & \\
\hline Update (lag 1-7) & & & & $1.072^{* * *}$ & & & & \\
\hline Comment (lag 1) & & & & & & $1.002^{* * *}$ & & \\
\hline Comment (lag 1-7) & & & & & & & & $1.000^{* * *}$ \\
\hline No. obs. & & 4025 & & 4025 & & 4025 & & 4025 \\
\hline \multicolumn{9}{|c|}{ Panel B: regressions based on specific types of comments } \\
\hline Explanatory variables & {$[1]$} & {$[2]$} & {$[3]$} & {$[4]$} & {$[5]$} & {$[6]$} & [7] & {$[8]$} \\
\hline Valuable info (lag 1) & $1.147^{* * *}$ & & & & & $1.116^{* * *}$ & & $1.106^{* * *}$ \\
\hline Offers help (lag 1) & & $1.331^{* * *}$ & & & & $1.175^{* *}$ & & $1.172^{* *}$ \\
\hline Knows product (lag 1) & & & $1.040^{* * *}$ & & & 0.976 & & 0.979 \\
\hline Expert claim (lag 1$)$ & & & & $1.218^{* * *}$ & & 1.065 & & 1.058 \\
\hline Second time (lag 1) & & & & & $1.084^{* * *}$ & $1.070^{* * *}$ & & $1.070^{* * *}$ \\
\hline Comment length (lag 1) & & & & & & & $1.002^{* * *}$ & $1.001^{* *}$ \\
\hline No. obs. & 4025 & 4025 & 4025 & 4025 & 4025 & 4025 & 4025 & 4025 \\
\hline \multicolumn{9}{|c|}{ Panel C: regressions with interaction terms } \\
\hline Variable considered & & \multicolumn{2}{|c|}{ Post funded } & \multicolumn{3}{|c|}{ Variable } & \multicolumn{2}{|c|}{ Variable $*$ post funded } \\
\hline Update (lag 1) & & \multicolumn{2}{|c|}{$1.800^{* * *}$} & \multicolumn{3}{|c|}{$2.070^{* * *}$} & \multicolumn{2}{|l|}{$0.562^{* * *}$} \\
\hline Comment (lag 1) & & \multicolumn{2}{|c|}{$1.629^{* * *}$} & \multicolumn{3}{|c|}{$1.029 * * *$} & \multicolumn{2}{|l|}{$0.974^{* * *}$} \\
\hline Valuable info (lag 1) & & \multicolumn{2}{|c|}{$1.517^{* * *}$} & \multicolumn{3}{|c|}{$1.255^{* * *}$} & \multicolumn{2}{|l|}{$0.902^{* * *}$} \\
\hline Offers help (lag 1) & & \multicolumn{2}{|c|}{$1.501^{* * *}$} & \multicolumn{3}{|c|}{$2.191^{* *}$} & \multicolumn{2}{|l|}{0.603} \\
\hline Knows product (lag 1) & & \multicolumn{2}{|c|}{$1.542^{* * *}$} & \multicolumn{3}{|c|}{$1.610^{* * *}$} & \multicolumn{2}{|l|}{$0.646^{* * *}$} \\
\hline Expert claim (lag 1) & & \multicolumn{2}{|c|}{$1.552^{* * *}$} & \multicolumn{3}{|c|}{$1.840^{* * *}$} & \multicolumn{2}{|l|}{$0.638^{* * *}$} \\
\hline Second time (lag 1) & & \multicolumn{2}{|c|}{$1.545^{* * *}$} & \multicolumn{3}{|c|}{$1.542^{* * *}$} & \multicolumn{2}{|l|}{$0.705^{* * *}$} \\
\hline Comment length (lag 1) & & \multicolumn{2}{|c|}{$1.586^{* * *}$} & \multicolumn{3}{|c|}{$1.004^{* * *}$} & \multicolumn{2}{|l|}{$0.997^{* * *}$} \\
\hline
\end{tabular}


A natural question is whether the content value of such comments remains similar after minimum funding is achieved, so that there is no longer uncertainty about whether investments take place. To investigate this issue, we add an interaction terms with Post Funded and report the results in Panel C of Table 6. Each line in the panel is a separate specification, which means that each type of update or comment is tested separately (similar to Models (1)-(5) and (7) in Panel B). We find that the impact of comments is significantly reduced in the post-funded period. Indeed, all the coefficients of the interaction term are smaller than 1 and statistically significant, except for Offers Help.

\subsection{Effect of peer investments}

Finally, we examine the effect of large peer investments on the funding dynamics. As discussed previously, larger investments convey additional information. First, wealthier individuals such as business angels who have greater capacity to evaluate this type of investment opportunities also make larger investments. A single large investment of 5000 EUR or even 10,000 EUR may signal the participation of more sophisticated investors and thus trigger the participation of other investors in subsequent days. Second, larger investments may convey the idea that these investors have engaged in more thorough due diligence. Because due diligence is costly, it is economically sensible only if someone makes a large investment. If that is the case, we expect a larger investment to trigger more participation by others. By contrast, withdrawals may trigger a reduction in investments, as they may be a signal that someone who invested early during the campaign received negative information and therefore decided to withdraw the money pledged.

Table 7 reports the results on peer effects. Again, next to the extra variables on peer investments, all the regressions include the variables of the baseline specification shown in Table 3. In Panel A of Table 7, we show the results for the full sample. We find that an investment of 5000 EUR or more during the last 7 days (Invest5k (lag 1-7)) has a positive and significant impact on investments on the following day. The economic significance, however, is rather small, as one such investment affects the number of investments only by 3.8\%. Other specifications and definitions of variables offer little support for peer investment effects. Moreover, withdrawals do not affect investment dynamics. One possible reason is that withdrawals are extremely rare and occur mostly in times of heavy bidding.

One potential concern about the analysis is that the first days of a campaign are very different from the rest. Agrawal et al. (2015) show that friends and family, who invest for very different reasons, supported many of the investments in the first days of a crowdfunding campaign. Therefore, peer investment effects may not be that strong during this early funding period. Panel B of Table 7 shows the same analysis as in Panel A, but excluding the first seven days of every campaign. This enables us to exclude days when peer investment effects are likely to have only marginal effects. Our results confirm that peer investment effects are stronger after the first seven days, as evidenced in Panel B. While withdrawals continue to have no impact, larger investments (whether at 5000 EUR or 10,000 EUR) have a positive and significant effect on investments. For example, an investment of at least 10,000 EUR increases investments on the subsequent day by $31.6 \%$. We consider these finding strong evidence for H5a but not H5b.

Table 7

Peer investments.

This table shows results of the baseline regressions, as specified in Section 4.3. Next to the variables reported in the table, this baseline regression also includes dummy variables for the first and last 7 days of campaigns, the day of the week, month of the year, and year dummies. All the variables reported below are defined in Appendix Table 1. The dependent variable is the number of investments in a specific campaign and day. Coefficients reported are incidence rate ratios. Data take panel-data structure. The method of estimation is the panel-data Negative Binomial regression with fixed effects. Significance levels (for coefficient being different from 1 ): * $<10 \%$, ${ }^{* *}<5 \%,{ }^{* * *}<1 \%$.

\begin{tabular}{|c|c|c|c|c|c|c|}
\hline \multicolumn{7}{|l|}{ Panel A: full sample } \\
\hline Explanatory variables & {$[1]$} & {$[2]$} & {$[3]$} & {$[4]$} & {$[5]$} & {$[6]$} \\
\hline Post funded dummy & $1.515^{* * *}$ & $1.698^{* * * *}$ & $1.519^{* * *}$ & $1.725^{* * *}$ & $1.741^{* * *}$ & $1.524^{* * * *}$ \\
\hline Invest5k (lag 1) & $1.038^{* * *}$ & & & & & \\
\hline Invest5k (lag 1-7) & & $1.038^{* * *}$ & & & & \\
\hline Invest10k (lag 1) & & & $1.095^{* * *}$ & & & \\
\hline Invest10k (lag 1-7) & & & & $1.056^{* * *}$ & & \\
\hline Withdrawals (lag 1) & & & & & 1.031 & \\
\hline Withdrawals (lag 1-7) & & & & & & 0.992 \\
\hline No. obs. & 4025 & 4025 & 4025 & 4025 & 4025 & 4025 \\
\hline \multicolumn{7}{|c|}{ Panel B: excluding the first seven campaign days } \\
\hline Explanatory variables & {$[1]$} & {$[2]$} & {$[3]$} & {$[4]$} & {$[5]$} & {$[6]$} \\
\hline Post funded dummy & $1.751^{* * *}$ & $1.718^{* * *}$ & $1.751^{* * *}$ & $1.721^{* * *}$ & $1.742^{* * *}$ & $1.747^{* * *}$ \\
\hline Invest5k (lag 1) & $1.066^{*}$ & & & & & \\
\hline Invest5k (lag 1-7) & & $1.094^{* * *}$ & & & & \\
\hline Invest10k (lag 1) & & & $1.316^{* * *}$ & & & \\
\hline Invest10k (lag 1-7) & & & & $1.159^{* * *}$ & & \\
\hline Withdrawals (lag 1) & & & & & 0.886 & \\
\hline Withdrawals (lag 1-7) & & & & & & 0.952 \\
\hline No. obs. & 3432 & 3432 & 3432 & 3432 & 3432 & 3432 \\
\hline
\end{tabular}




\title{
6. Conclusions
}

Several European countries as well as the United States and Canada have changed their securities regulation in recent years to promote equity crowdfunding activities, while also ensuring that investors obtain a minimum level of investor protection (Cumming and Johan, 2013; Hornuf and Schwienbacher, 2017b). Most of these issuances remain outside the scope of the general prospectus regime, so issuing securities for startups involve limited costs. We find that a key factor influencing investments by the crowd is how the portal allocates investment tickets. In particular, funding dynamics are affected by how securities are allotted to investors. Consistent with our predictions, an auction mechanism induces late investments, while an FCFS mechanism induces quick investments during the very first days. Given the difference in dynamics, the timing of information disclosure is crucial.

Moreover, our study finds that crowd investors do react to information disclosure during the campaign, but investment decisions are also rooted in the collective network interactions. Consistent with research on consumer behavior in the digital economy, we also observe a sharp decay of activities after the first couple of days, which indicates that information is so plentiful on the Internet that attention becomes quickly limited. Furthermore, the study offers evidence that investors regard investments by larger, more sophisticated investors as valuable signals. This finding is important, as many regulators have legally limited the amount that can be invested by a single investor.

A worthy follow-up research question is whether the market mechanism affects campaign outcome and, ultimately, firm performance. While the FCFS mechanism helps obtain early momentum, the auction mechanism could reduce overall funding costs for the entrepreneur if the campaign enters a fierce auction process. We leave these issues open for future research.

\section{Appendix A}

\section{Appendix Table 1}

List and definitions of variables (panel data).

\author{
Dependent variable \\ Investments: The number of investments made by crowd investors on day $\mathrm{t}$ in a particular campaign $\mathrm{i}$. \\ Information disclosure variables
}

Comment (lag 1-7): The number of comments posted on the portal website by crowd investors during the days t-1 to t-7 of a campaign. Similarly, Comment

(lag 1) gives the number of comments posted on the portal website by crowd investors at day $\mathrm{t}-1$ of a campaign.

Comment length (lag 1): The average length in number of letters of comments posted the previous day of a campaign, where "no comment" equals 0.

Expert claim (lag 1): The number of comments posted during the previous day of a campaign in which investor claims to be an expert.

Knows product (lag 1): The number of comments posted during the previous day of a campaign in which investor claims to already know the product.

Offers help (lag 1): The number of comments posted during the previous day of a campaign in which investor offers personal help.

Second time (lag 1): The number of comments posted during the previous day of a campaign in which investor says he or she is investing a second time (either in that same round or a previous round).

Update (lag 1-7): The number of updates posted on the portal website by the entrepreneur during the days t-1 to t-7 of a campaign. Similarly, Update (lag 1) gives the number of updates posted on the portal website by the entrepreneur at day $\mathrm{t}-1$ of a campaign.

Valuable info (lag 1): The number of comments posted during the previous day of a campaign that includes valuable information for product and/or market development. Peer effect variables

Invest5k (lag 1-7): The number of investments that had an amount of 5000 EUR or higher during the days t-1 to t-7 of a campaign. Similarly, Invest5k (lag 1) gives the number of investments that had an amount of 5000 EUR or higher at day $\mathrm{t}-1$ of a campaign.

Invest10k (lag1-7): The number of investments that had an amount of 10,000 EUR or higher during the days t-1 to t-7 of a campaign. Similarly, Invest10k

(lag 1) gives the number of investments that had an amount of 10,000 EUR or higher at day t-1 of a campaign.

Withdrawals (lag 1-7): The number of withdrawals during the days t-1 to t-7 of a campaign. Similarly, Withdrawals (lag 1) gives the number of withdrawals at day $\mathrm{t}-1$ of a campaign.

End-of-campaign variables

90\%-Limit: Dummy variable that equals 1 if the total amount of money pledged by crowd investors represents at least $90 \%$ of the funding limit (i.e., the maximum amount that the entrepreneur is willing to raise) and 0 otherwise.

95\%-Limit: Dummy variable that equals 1 if the total amount of money pledged by crowd investors represents at least $95 \%$ of the funding limit (i.e., the maximum amount that the entrepreneur is willing to raise) and 0 otherwise.

Collective attention variables

Day dummies: Dummy variable that equals 1 for a particular day of the campaign, starting with day $1,2 \ldots, 7$ day and ending with the 7 th last day till the last day of the campaign.

Control variables

Active campaigns: The number of campaigns across all four portals that accept investments on day t (including the current campaign).

Amount: The amount in euros invested by crowd investors on day $t$.

Auction: Dummy variable that equals 1 if securities are allocated to crowd investors under an auction mechanism and 0 if under a first-come-first-serve mechanism. Only Innovestment offers an auction mechanism.

Competing investments: The number of investments made on day t across all other competing campaigns conducted on the portals studied (including the current campaign).

Duration: The number of days elapsed from the start until the end of a campaign.

Funding goal: The minimum funding goal as defined by the startup and portal at $t=0$.

Directors: Number of directors in the startup at time of the campaign. Source: Orbis database.

Patents: Number of patents held by the startup at time of the campaign. Source: Orbis database.

Post funded: Dummy variable that equals 1 for the days a campaign has surpassed the Funding Goal and 0 otherwise. 
Appendix Table 2

Definition and examples of comment coding.

\begin{tabular}{l} 
Coding of comments \\
\hline Valuable info: The investor gives suggestions on \\
how to improve the product or website, on how \\
to access more customers, or on how to extend \\
the same idea to another market. Note: We were \\
not able to assess whether the information \\
provided is indeed "valuable" but coded whether \\
"potentially valuable ideas" are offered. For \\
example, stating "Please also expand to \\
Switzerland" is not a valuable comment, as it \\
might be the result of the investor living there \\
and being interested in having a shop nearby for \\
personal reasons. However, stating "Please \\
expand to Switzerland because no comparable \\
product exists on the market" might be a \\
potentially valuable idea.
\end{tabular}

Offers help: The investor offers personal help to the startup or founder.

Knows product: The investor states that he or she has already tried the product.

Expert claim: The investor claims to know the market or have experience in that same industry. Note: stating "I was convinced after I asked a friend" is not a valid comment, but stating "I work in the same industry and see the potential" would be a valid comment.

Second time: The investor states that he or she pledges more money, either during the same campaign or because he or she participated in the previous campaign of that startup.

\author{
Examples
}

a) "[...] Allerdings habe ich einen persönlichen Kundenbereich sehr vermisst. [...]"

b) "Schnell mit Apps auch für Smartphones (auch Blackberry) nutzbar machen und dann so richtig durchstarten. [...]"

c) "[...] Googlesuche zu "biometrisches passbild online erstellen" zeigt ePortrait erst auf Seite 3...ganz unguenstig...schonmal Suchmaschinenoptimierung betrieben? [...]"

d) " $[. .$.$] Angenommen einer meiner Mitarbeiter$ ist krank oder hatte gerade eine schwere OP, da wäre es schon toll, ihm so eine "Werden Sie doch schnell wieder Gesund" - Box nach Hause oder ins Krankenhaus zu senden, wo halt gesunde Dinge und etwas zum Naschen bei der schnellen Regeneration nachhelfen und mein Angestellter sieht, dass er als Mensch auch Wert geschätzt wird und nicht nur einfach die Ressource Arbeiter ist. [...]"

a) "[...] Wenn ich unterstützen kann lasst es mich wissen, habe viele Kontakte! [...]"

b) "[...] Ich hoffe, ihr könnt auch meinen Arbeitgeber von euch überzeugen;-)... Ich werde fleißig für euch werben! [...]"

c) "Tolle Idee, falls ihr auch Teestuben etc. in der Schweiz beliefern möchtet, bitte melden!"

d) "[...] Stehe bei Interesse gerne mit Rat und Tat zur Seite (Corporate Finance Spezialist bei einer Großbank). [...]"

a) "[...] Bin schon seit längerem Abonnent bei Sommelier Privee und kann somit sagen, dass sich dieses Angebot in einem eher recht dichten Markt durch kleine aber feine Details unterscheidet. [...]"

b) "Das April-Paket war eine geniale Kombination von Leckereien, vielen Dank!"

a) "Wir nutzen Carla als Vertriebsagentur im Shoefashion-Bereich supergerne und glauben an weitere Erfolge des Teams rund um Ali."

b) "[...] Hallo, ich weiß zwar nicht wie hoch die Entwicklungskosten für die Blackberry App sind, aber meint ihr das ist mittel- bis langfristig sinnvoll, wenn man bedenkt, dass der Marktanteil bei neuverkauften Geräten bei nur ca. 6\% liegt???. [...]"

c) "Schaut Euch auch einmal insbesondere die nord-europäischen Märkte an. Beispielsweise gibt es bei vielen schwedischen Häusern statt Kuchen am Nachmittag solche Art von Snacks. [...]"

a) "Noch mal nachgelegt!"

b) "Ich investiere zum zweiten Mal [...]"

c) "Nachgelegt!!! Meine Empfehlung: KAUFEN!!! :-)"

d) "Nochmal ein kleiner Nachschlag auf de Zielgeraden... :-)"

e) "Und wieder mit 5 euro dabei"
Translation

a) “[...] But I really missed a personalized costumer area [on the website] [...]"

b) "Quickly implement an app for smartphones (including Blackberry) and then touch-and-go. [...]"

c) "[...] A google search for "create a biometric picture yourself online" lists ePortrait only on page $3 . .$. very bad...have you ever done a search engine optimization? [...]"

d) "[...] Imagine one of my employees gets sick or experienced a severe operation. Then it would be nice to send him a "Get well soon" box home or to the hospital, which includes heathy things and some goodies that help him recover quickly and my employee realizes that he is valued as a human being and not just a labor input factor. [...]"

a) "[...] If I can support you, let me know, I have a lot of contacts! [...]"

b) "[...] I hope, you can also convince my employer ;-) ... I will promote you! [...]"

c) "Great idea, if you want to serve tea shops in Switzerland, please contact me"

d) "[...] If you are interested I am willing to help with advice and action (Corporate Finance specialist at a large bank). [...]"

a) $[. .$.$] I am a long term subscriber of Somme-$ lier Privé and can thus say that the products differentiate themselves because of small and crucial details in a very tight market [...]"

b) "The April-box was a great combination of goodies, many thanks!"

a) "We gladly use Carla as sales agency in the shoefashion-area and believe in the success of the teams working with Ali"

b) "[...] Hello, I don't know how high the development costs are for a Blackberry app, but do you believe this is useful in the medium and long run, if you consider that the market share for newly sold devices is only $6 \% ? ? ?$ [...]"

c) "Have a look at the northern European markets. For example, in Sweden there are many shops that serve this type of snacks in the afternoon instead of cake. [...]"

a) "Added more [money]."

b) "I invest a second time [...]"

c) "Added more [money]!!! My recommendation: BUY!!! :-)"

d) "Topping up the ante on the way to the funding goal... :-)"

e) "And I participate again with 5 EUR."

\section{References}

Agrawal, Ajay, Catalini, Christian, Goldfarb, Avi, 2015. Crowdfunding: geography, social networks, and the timing of investment decisions. J. Econ. Manag. Strateg. 24 (2), 253-274

Agrawal, Ajay, Catalini, Christian, Goldfarb, Avi, 2016. Are syndicates the killer app of equity crowdfunding? Calif. Manag. Rev. 58 (2), $111-124$.

Ahlers, Gerrit K.C., Cumming, Douglas, Guenther, Christina, Schweizer, Denis, 2015. Equity crowdfunding. Enterp. Theory Pract. 39 (4), $955-980$.

Ariely, Dan, Ockenfels, Axel, Roth, Alvin E., 2005. An experimental analysis of ending rules in internet auctions. RAND J. Econ. 36 (4), $891-908$.

Ball, Ray, Brown, Phillip, 1968. An empirical evaluation of accounting income numbers. J. Account. Res. 6 (2), 159-178.

Baltagi, Badi H., 2008. Econometric Analysis of Panel Data. Wiley, West Sussex.

Ben-Shahar, Omri, Schneider, Carl E., 2014. More Than You Wanted to Know: The Failure of Mandated Disclosure. Princeton University Press, Princeton, NJ. 
Bikhchandani, Sushil, Hirshleifer, David, Welch, Ivo, 1992. A theory of fads, fashion, custom, and cultural change as information cascades. J. Polit. Econ. 100 (5), 992-1026.

Block, Jörn, Hornuf, Lars, Moritz, Alexandra, 2017. Which updates during an equity crowdfunding campaign increase crowd participation? Small Bus. Econ. (forthcoming).

Braun, Reiner, Eidenmüller, Horst, Engert, Andreas, Hornuf, Lars, 2013. Does charter competition foster entrepreneurship? A difference-in-difference approach to European company law reforms. J. Common Mark. Stud. 51 (3), 399-415.

Burtch, Gordon, Ghose, Anindya, Wattal, Sunil, 2015. The hidden cost of accommodating crowdfunder privacy preferences: a randomized field experiment. Manag. Sci. 61 (5), 949-962.

Chapman, Gretchen B., Johnson, Eric J., 2002. The psychology of intuitive judgment. In: Gilovich, Thomas, Griffin, Dale, Kahneman, Daniel (Eds.), Heuristics and Biases. Cambridge University Press, Cambridge.

Cumming, Douglas J., Johan, Sofia, 2013. Demand driven securities regulation: evidence from crowdfunding. Ventur. Cap. 15, 361-379.

Cumming, Douglas J., Leboeuf, Gaël, Schwienbacher, Armin, 2014. Crowdfunding Models: Keep-It-All vs. All-or-Nothing. SSRN working paper, available at:. http:// ssrn.com/abstract $=2447567$.

Dorfleitner, Gregor, Hornuf, Lars, Schmitt, Matthias, Weber, Martina, 2017. FinTech in Germany. Springer, Heidelberg.

Fama, Eugene F., 1965. The behavior of stock-market prices. J. Bus. 38 (1), 34-105.

Fama, Eugene F., Fisher, Lawrence, Jensen, Michael, Roll, Richard, 1969. The adjustment of stock prices to new information. Int. Econ. Rev. 10 (1), 1-21.

Günther, Christina, Johan, Sofia, Schweizer, Denis, 2017. Is the crowd sensitive to distance? - How investment decisions differ by investor type. Small Bus. Econ. (forthcoming).

Hausman, Jerry, Hall, Bronwyn H., Griliches, Zvi, 1984. Econometric models for count data with an application to the patent-R\&D relationship. Econometrica 52 (4), 909-938.

Hodas, Nathan O., Lerman, Kristina, 2013. Attention and visibility in an information-rich world. Proceedings of the 2nd International ICME Workshop on Social Multimedia Research.

Hornuf, Lars, Neuenkirch, Matthias, 2017. Pricing shares in equity crowdfunding. Small Bus. Econ. 48 (4), $795-811$.

Hornuf, Lars, Schmitt, Matthias, 2016. Success and failure in equity crowdfunding. CESifo DICE Report 14 (2), 16-22.

Hornuf, Lars, Schwienbacher, Armin, 2017a. Internet-based entrepreneurial finance: lessons from Europe. Calif. Manag. Rev. (forthcoming).

Hornuf, Lars, Schwienbacher, Armin, 2017b. Which securities regulation promotes equity crowdfunding? Small Bus. Econ. 49 (3), $579-593$.

Kagel, John, Levin, Dan, 2001. Behavior in multi unit demand auctions: experiments with uniform price and dynamic Vickrey auctions. Econometrica 69 (2), $413-454$.

Kickstarter, 2012. Blockbuster effects. http://www.kickstarter.com/blog/blockbuster-effects, Accessed date: 6 January 2015.

Klöhn, Lars, Hornuf, Lars, Schilling, Tobias, 2015. The regulation of crowdfunding in the draft small investor protection act: content, consequences, critique, suggestions. Eur. Company Law 13 (2), 56-66.

Kuppuswamy, Venkat, Bayus, Barry L., 2017. Crowdfunding creative ideas: the dynamics of project backers. In: Cumming, Douglas, Hornuf, Lars (Eds.), The Economics of Crowdfunding Startups, Portals and Investor Behavior. Palgrave Macmillan, London (forthcoming).

NESTA, 2014. Understanding Alternative Finance: The UK Alternative Finance Industry Report 2014. available at:. https://www.nesta.org.uk/sites/default/files/understanding-alternative-finance-2014.pdf.

Roth, Alvin E., Ockenfels, Axel, 2002. Last-minute bidding and the rules for ending second-price auctions: evidence from eBay and Amazon auctions on the internet. Am. Econ. Rev. 92 (4), 1093-1103.

Scholes, Myron, 1969. A Test of the Competitive Hypothesis: The Market for New Issues and Secondary Offerings. doctoral thesis. University of Chicago.

Signori, Andrea, Vismara, Silvio, 2016. Returns on Investments in Equity Crowdfunding. SSRN working paper, available at:. http://ssrn.com/abstract=2765488.

Spence, Michael, 1973. Job market signaling. Q. J. Econ. 87 (3), 355-374.

Vickrey, William, 1961. Counterspeculation, auctions, and competitive sealed tenders. J. Financ. 16 (1), 8-37.

Vismara, Silvio, 2016. Equity retention and social network theory in equity crowdfunding. Small Bus. Econ. 46 (4), 579-590.

Vismara, Silvio, 2017. Information cascades among Investors in equity crowdfunding. Enterp. Theory Pract. (forthcoming).

Vulkan, Nir, Åstebro, Thomas, Sierra, Manuel F., 2016. Equity crowdfunding: a new phenomena. J. Bus. Venturing Insights 5, 37-49.

Vuong, Quang H., 1989. Likelihood ratio tests for model selection and non-nested hypotheses. Econometrica 57 (2), $307-333$.

Wu, Fang, Huberman, Bernardo, 2007. Novelty and collective attention. Proc. Natl. Acad. Sci. 104 (45), 17599-17601. 